\title{
Role of Zinc and Selenium in Oxidative Stress and Immunosenescence: Implications for Healthy Aging and Longevity
}

\section{Eugenio Mocchegiani and Marco Malavolta}

\section{Contents}

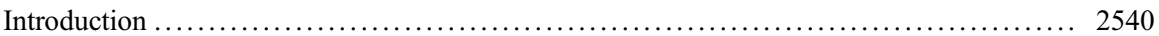

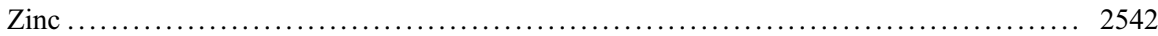

Zinc Biology and Homeostasis ........................................ 2542

Metallothioneins, Immunosenescence, and Aging ............................ 2544

Zinc Transporters, Immunosenescence, and Aging .......................... 2546

Rationale for Zinc Supplementation in Aging ............................. 2547

Zinc Interaction with Other Micronutrients and Zinc Toxicity ................... 2551

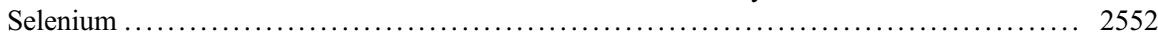

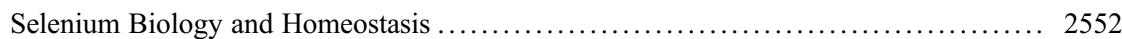

Selenium Homeostasis, Immunosenescence, and Aging ........................ 2554

Interrelationship Between Zinc and Selenium: Implications for Healthy Aging ........ 2560

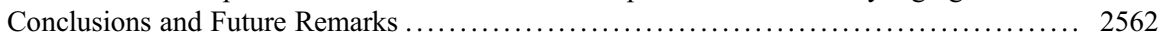

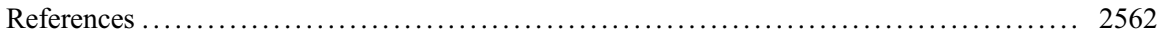

\begin{abstract}
Aging is a complex process that includes gradual and spontaneous biochemical and physiological changes which contributes to a decline in performance and increased susceptibility to diseases. $\mathrm{Zn}$ and $\mathrm{Se}$ are essential trace elements that play a pivotal role in immune functions and antioxidant defense and, consequently, are claimed to play also a role in successful aging trajectories.
\end{abstract}

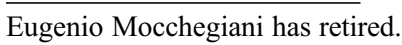

E. Mocchegiani

Nutrition and Aging Centre, Scientific and Technological Pole INRCA, Ancona, Italy e-mail: eugeniomocch58@gmail.com

M. Malavolta $(\square)$

Advanced Technology Center for Aging Research, Scientific Technological Area, IRCCS-INRCA, Ancona, Italy

e-mail:m.malavolta@inrca.it 
Consistently with their nature of essential trace elements, a plethora of data obtained "in vitro" and "in vivo" (in humans and animal models) support the relevance of $\mathrm{Zn}$ and $\mathrm{Se}$ for both the innate and adoptive immune response. Moreover, $\mathrm{Zn}$ and Se are strictly involved in the synthesis and regulation of activity of proteins and enzymes, e.g., metallothioneins (MT) and glutathione peroxidase (GPX), that are necessary for our endogenous antioxidant response. This is clearly important to protect our cells from oxidative damage and to slow the decline of our immune system with aging. Age-related changes affecting tissue levels of $\mathrm{Zn}$ and Se may indicate that the risk of $\mathrm{Zn}$ and Se deficiency increases with aging. However, it is still unclear which of these changes can be the consequence of a "real deficiency" and which can be part of our physiological compensatory response to the accumulating damage occurring in aging. Furthermore, the upregulation of antioxidant proteins ( $\mathrm{Zn}$ and Se dependent) may be a manifestation of self-induced oxidative stress. By the way, $\mathrm{Zn}$ and Se dependent proteins are modulated not only by nutritional status, but also by wellknown hallmarks of aging that play antagonistic functions, such as the deregulated nutrient sensing pathways and cellular senescence. Thus, it is not an easy task to conduct $\mathrm{Zn}$ or Se supplementation in elderly and it is emerging consistent that these kind of supplementation requires an individualized approach. Anyway, there is consistent support that supplementation with $\mathrm{Zn}$ using doses around $10 \mathrm{mg} /$ day is generally safe in elderly and may even improve part of immune performances in those subjects with a baseline deficiency. Regarding Se supplementation, it may induce both beneficial and detrimental effects on cellular immunity depending on the form of Se, supplemental dose, and delivery matrix. The nutritional association of supplements based on "Zn plus Se" is hypothesized to provide additional benefits, but this will likely need a more complex individualized approach. The improvement of our knowledge around screening and detection of $\mathrm{Zn}$ and Se deficiency in aging could lead to substantial benefits in terms of efficacy of nutritional supplements aimed at ameliorate performance and health in aging.

\section{Keywords}

Zinc $\cdot$ Selenium $\cdot$ Immosenescence $\cdot$ Oxidative stress $\cdot$ Zinc transporters $\cdot$ Metallothioneins - Selenoproteins - Deregulated nutrient sensing pathways $\cdot$ Cellular senescence $\cdot$ Supplementation $\cdot$ Age-related diseases $\cdot$ Aging $\cdot$ Longevity

\section{Introduction}

Biological Aging is a process driven by molecular damage, molecular heterogeneity, and metabolic imbalance which determinates increased susceptibility to diseases and impaired adaptation to changes in environmental conditions (Rattan 2016). Alterations in the immune functions play a fundamental role in aging. The term "immunosenescence" has been coined to describe the changes that occur with age in 
the immune system and that lead to a higher incidence of infection, cancer, and autoimmune disease (Fulop et al. 2010; Pawelec et al. 2014). Immunosenescence involves a shift in function of both adaptive and innate immune cells, which can be resumed in a reduced capacity to recognize new antigens and in the occurrence of systemic low-grade chronic inflammation. This phenomenon, termed "inflamaging" (Franceschi et al. 2000) is likely the result of immunosurveillance of chronic infections (chronic antigen stress) (Pawelec et al. 2014) combined with accumulating senescent cells which, in turn, are a rich source of pro-inflammatory factors collectively termed the "Senescence-associated secretory phenotype" (SASP) (Campisi 2014). In analogy with aging, immunosenescence in humans is very heterogeneous and can be described as a complex mosaic resulting from the interaction of a variety of environmental, stochastic, and genetic-epigenetic variables. It is likely that, through a favorable combination of these factors, centenarians avoid or delay the major inflammation-driven age-related diseases, such as cardiovascular disease (CVD), diabetes mellitus (DM), Alzheimer disease (AD), and cancer (Bürkle et al. 2007) despite showing some markers of inflammation.

Diet and nutritional factors are known to play a role in the preservation of our immune system in aging. Deficiencies of both macro- and micronutrients in aging is strictly related to global impairments of the immune functions and appearance of age-related diseases (Lesourd 2006). Several causes contribute to micronutrient deficiencies in elderly. First of all, the poor socioecon3omic condition present in a large part of old people may lead to a consumption of inexpensive foods deficient in micronutrients (Kant 2000). The gap is worsened by loss of appetite, lack of teeth, intestinal malabsorption, and subclinical diseases that lead to the final result of frailty, disability, and mortality (Semba et al. 2006). By contrast, changes in diet and exercise patterns appears to be effective in the prevention of late-onset nutritionrelated conditions, especially when these are instituted early in life (Chernoff 2001).

Available data do indicate that essential vitamins and trace elements are necessary for normal immune function (Maggini et al. 2007), but conclusive studies demonstrating that vitamin or mineral supplements can boost immune function are currently lacking. Hence, there is evidence that further supplementation of micronutrients beyond the recommended daily intake can improve immune function (Dharmarajan 2015).

However, clear roles exist for vitamin and trace element supplementation in states of deficiency and in subgroups of older adults at high risk for deficiency. By the other way, the prevalence of certain nutritional deficiencies in the geriatric population (e.g., Zinc and Selenium) is sufficiently high that certain supplements may be indicated (Ames 2006).

We herein review the role of Zinc and Selenium for our immune system (Buttriss 2000) and describe the mechanisms through which they affect immunosenescence. Epidemiological and clinical evidence have shown that in most developing countries deficiencies of these micronutrients are partly responsible for the severity of infectious disease, morbidity, and mortality in malnourished children (Bhaskaram 2002; Bailey et al. 2015) as well as in elderly (Meydani 2001) and critically ill patients (Mertens et al. 2015). These two trace elements display a common pivotal role in 
establishing the cellular antioxidant response as well as in mounting a proper immune response, which in turn may be useful to prevent excessive accumulation of senescent cells in aging and to reduce the senescence-associated increase of chronic inflammatory mediators.

\section{Zinc}

\section{Zinc Biology and Homeostasis}

\section{Biological Role of Zinc}

Zinc is one of the most important trace elements in the body, although its presence in nature does not exceed $0.02 \%$ (Mills 1989). The major characteristics of zinc include a highly concentrated charge, a small radius $(0.65 \mathrm{~A})$, no variable valence (low risk of free radical production), ready passage from one symmetry in its surroundings to another without exchange, rapid exchange of ligands (on and off reactions), and binding mostly to S- and N-donors in biological systems. These properties enable zinc to play a major biological role as a catalyst. Zinc is essential for the activity of more than 300 enzymes influencing the activity of zinc dependent antioxidant enzymes, such as superoxide dismutase (SOD) and various organ functions having a secondary effect on the immune system (Rink and Gabriel 2000). Zinc is present in "zinc finger domains" of transcription factors and in a multitude of proteins, peptides, enzymes, hormones, and cytokines, which act in maintaining body homeostasis (Coleman 1992; Berg and Shi 1996). Zinc also regulates mRNA stability (Taylor and Blackshear 1995) and extracellular matrix (Vallee and Falchuk 1993). Zinc binds enzymes, proteins, and peptides with different binding affinity (kd) ranging from $10^{-2}$ to $10^{-14} \mathrm{~mol} / \mathrm{l}$ (Mocchegiani et al. 1998). Some of these enzymes may be activated by zinc, as for instance the thymic hormone named thymulin, which loses its activity in absence of zinc (Fabris et al. 1984), while others may be inactivated. Zinc also regulates cell cycle and apoptosis (Fraker 2005) with an optimal range of concentration that has been well defined by studies on genomic stability "in vitro."

These studies, performed on various cellular models, suggest that genomic instability is minimized when $\mathrm{Zn}$ concentration in culture medium is comprised between 4 and $16 \mu \mathrm{M}$ (Ho and Ames 2002; Ho et al. 2003; Sharif et al. 2011). Although, it is currently unknown whether these results can be translated "in vivo," where additional factors including blood composition, genetic background, aging, and diseases can affect the response, these studies "in vitro" confirm that an excess of $\mathrm{Zn}$ is dangerous for cellular health in equal measure to $\mathrm{Zn}$ deficiency.

A very recent study altered the zinc balance within Caenorhabditis elegans to examine how changes in zinc burden affect longevity and healthspan in an invertebrate animal model. The authors found that increasing dietary zinc levels decreased the mean and maximum life span of the worms, whereas treatment with a zinc-selective chelator increased their mean and maximum life span. The life span modulating effects were mediated by DAF-16, HSF-1, and SKN-1 proteins, which suggest the involvement of the insulin/IGF-1 pathway. These results are somewhat supporting the idea that zinc itself has a role as an antagonistic pleiotropy player (Kumar et al. 2016). 
By the way, it has been just recently hypothesized that reduced zinc levels in serum during human aging may reflect the homeostatic shade from a general systemic "growth and reproduction" status typical of juvenile age to a "repair and maintenance" status that evolved to preserve health status during old age (Malavolta et al. 2015).

The cellular basis for the impact of low and high $\mathrm{Zn}$ status has been studied for many years but it is only recently that the complexity of $\mathrm{Zn}$ homeostasis has been appreciated. The advance in the knowledge around the major intracellular $\mathrm{Zn}$ binding proteins, namely the Metallothioneins (MT) and the discovery, cloning, and characterization of $24 \mathrm{Zn}$ transporter proteins, has highlighted the role of free $\mathrm{Zn}$ ion and the fluxes of $\mathrm{Zn}$ ions between extracellular, cellular, and intracellular compartments. Indeed, these $\mathrm{Zn}$ signals can initiate pathways which have tight analogies with those discovered for calcium signaling, albeit in the sub- and nanomolar range (Haase and Rink 2014).

\section{Metallothioneins}

Metallothioneins (MT) are a group of low-molecular-weight metal-binding proteins who have high affinity for zinc $\left(\mathrm{kd}=1.4 \times 10^{-13} \mathrm{M}\right)$ (Kagi and Schaffer 1998). MT exist in different isoforms characterized by the length of amino acid chain: isoform I, II, III, e IV mapped on chromosome 16 in man and on chromosome 8 in mice with complex polymorphisms (West et al. 1990). The more common isoforms are I and II; the isoform III, also called growth inhibitory factor (GIF), is mostly expressed in brain tissues while the isoform IV is restricted in squamous epithelia. MT contain 20 cysteines which bind seven zinc atoms through mercaptide bonds that have the spectroscopy characteristics of metal thiolate clusters (Maret and Vallee 1998). The zinc/cysteine clusters are of two different types. In the beta-domain cluster, three bridging and six terminal cysteine thiolates provide a coordination environment that is identical for each of the three zinc atoms. In the alpha-domain clusters, there are two different zinc sites; two of them have one terminal ligand and three bridging ligands, respectively, while the other two have two terminal and two bridging ligands (Maret and Vallee 1998).

MT can act as an antioxidant since zinc-sulfur cluster is sensitive to changes of cellular redox state and oxidizing sites in MT (reduced thiol groups) induce the transfer of zinc from its MT-binding sites to those of lower affinity in other proteins (Kagi and Schaffer 1998).

In response to oxidative or nitrosative stress, Zn-MT release free zinc ions. The released free zinc ions are used to confer the biological activity to some zincdependent antioxidant enzymes and to other proteins involved in DNA repair, as well as to upregulate the gene expression of various factors involved in the antioxidant response (Mocchegiani et al. 2013). Hence, MT are able to transduce stress signals into free zinc ion signals which are immediately compensated by the activity of $\mathrm{Zn}$ transporters and subsequently downregulated by a feedback mechanism that involves the gene expression of MT themselves. This mechanism is also involved in regulation of nitric oxide (NO) pathways (Bogdan et al. 2000) as NO induces the release of zinc from MT, via S-nitrosylation (Zangger et al. 2001). The release of zinc by MT, via s-nitrosylation, contributing to raise the intracellular free zinc ions concentration, plays a crucial role in modulating the production of pro-inflammatory cytokines and in the activation of immune cells (Rink and Haase 2007). 


\section{Zinc Transporters}

Free zinc ion levels are also regulated by special proteins named zinc transporters, which in turn appear to be also specifically involved through regulation of cellular zinc homeostasis via influx, efflux, or vesicular sequestration (Cousins and McMahon 2000; Eide 2006). Two families of zinc transporters have been identified. The ZnT family decreases cytoplasmic zinc concentrations by secretion, sequestration, or efflux, whereas the ZIP family increases cytoplasmic zinc influx or release of stored zinc (Eide 2006).

The huge network based on Zn transporters and MT suggest how much critical is a tight regulation of zinc ion availability. Moreover, the timely release, efflux, and influx of $\mathrm{Zn}$ ions is known to virtually affect all aspects of innate and adaptive immunity. Several molecular targets, including phosphatases, phosphodiesterases, caspases, and kinases, suggest that zinc ions are like a second messenger that regulate signal transduction in various kinds of immune cells (Mocchegiani et al. 2004; Haase and Rink 2014). This phenomenon clearly explains why in vivo zinc deficiency alters the number and function of neutrophil granulocytes, monocytes, natural killer (NK), T, and B cells.

\section{Metallothioneins, Immunosenescence, and Aging}

The redox properties of MT contribute to make this protein a crucial defense against ionizing and UV radiations (Cai et al. 1999), heavy metals (mercury, cadmium), lipid peroxidation, reactive oxygen species, oxidative stress caused by anticancer drugs, and conditions of hyperoxia (Sato and Kondoh 2002). This protective role of MT has been studied especially in young-adult MT knockout mice (null mice) for short periods of exposure to toxic metals, such as cadmium for 10 weeks (Habeebu et al. 2000) or mercury (single injection and the effect of mercury analyzed 3 days after the injection) (Satoh et al. 1997), or to anticancer agents for 48-72 h (Kondo et al. 1997), or in presence of an excess of zinc or zinc deficiency for 3 weeks (Kelly et al. 1996).

Expression of MT is mediated by zinc (directly via MRE responsive elements in the promoter), glucocorticoids (via glucocorticoid responsive element in the promoter), and other stressor agents as well as from inflammatory cytokines, such as IL-1, IL-6, IFN-a, TNF-a (Davis and Cousins 2000). These findings clearly suggest the existence of a strong interplay between MT and the immune system. An important link between cytokines and MT seems to be STAT (signal transducers and activators of transcription) responsive element observed in the promoter of MT as well as the nitric oxide pathway. It is remarkable that cytokines reported to increase inducible NO synthase (iNOS) expression (IL-1 and TNF-a) have also induced the expression of MT (Zangger et al. 2001). This induction is likely the indirect consequence of the release of free zinc from preexisting MT via S-nitrosylation caused by NO. This process is particularly important for the production of thymic hormone (thymulin) from thymic epithelial cells. Indeed, IL-1 induces thymic uptake of zinc (Coto et al. 1992), which is subsequently made available for the activity of thymulin by a process that involve the redox status of MT (Savino et al. 1984). 
MT have been also found to be released to the extracellular environment in a number of different compartments, including cell culture media, serum, urine, bronchoalveolar spaces, liver sinusoids, and inflammatory lesions. Albeit a very small amount of MT can be found in the extracellular environment (e.g., around $1 \mu \mathrm{M}$ in serum), these proteins may support the beneficial movement of leukocytes to the site of inflammation representing a "danger signal" for the immune cells and modifying the character of the immune response when cells sense cellular stress (Yin et al. 2005).

Hence, MT are involved in several mechanisms that support immune function. What is still uncertain is the role of these proteins in aging and immunosenescence. In particular, there have been concerns around the possibility that MT may retain their protective role during chronic stress and inflammatory conditions associated with the major disease of aging (Mocchegiani et al. 2000a). In the case of cancer, for example, MT have been proven as an important barrier against carcinogenesis (Dziegiel et al. 2016; Malavolta et al. 2016) but, once malignant cells are formed these proteins may help cancer cells to survive and proliferate. Several studies have disclosed MT expression as a prognostic factor for tumor progression and drug resistance in a variety of cancers, including breast, prostatic, ovarian, head and neck, nonsmall cell lung cancer, melanoma, and soft tissue sarcoma (Eckschlager et al. 2009; Dziegiel et al. 2016). This action is consistent with the original biological role of MT, as these proteins are part of the defensive intracellular stress response. Additionally, elevated levels of extracellular MT, as detected at sites of inflammation and in certain types of neoplastic lesions, have been shown to display an immunosuppressive function (Youn and Lynes 1999). By contrast, there are cases where MT have been found to provide additional benefit in chronic inflammation, especially in cancer therapy. Indeed, while cancer cells overexpressing MT appear in general less sensitive to chemotherapeutic drugs, cancers where MT are progressively silenced are more sensitive to drugs following expression of specific MT isoforms in presence of zinc (Pedersen et al. 2009; Arriaga et al. 2014). These studies suggest that there is not a common role and that different MT isoforms might be differently associated with either chemoresistance or sensitivity to cancer drugs.

In the case of other chronic age-related diseases, it was hypothesized that the expression of MT, continuously stimulated by the persistence of inflammatory mediators (e.g., IL-6), could lead to a detrimental sequestration of zinc ions with potential functional consequences on the immunity of frail aged individuals (Mocchegiani et al. 2000a, b). Observational studies performed (a) in PBMCs from centenarians, which display lower MT expression compared to elderly aged 70-80 years, (Mocchegiani et al. 2002a); (b) in PBMC from Down's syndrome (syndrome which presents some features of accelerated aging and immunosenescence) subjects, which display levels of MT comparable to elderly subjects (Mocchegiani et al. 2002a), and (c) studies in mice models of athropic thymus, which display overexpression of MT (Mocchegiani et al. 2002b), have contributed to argue the hypothesis against a preserved functional role of MT in aging.

However, it has been more recently documented that MT expression declines with "in vitro" aging of PBMCs, thus suggesting that the low levels of MT observed in PBMCs of centenarians could simply be the consequence of the increasing 
accumulation of senescent cells in blood (Malavolta et al. 2008) or other phenomena related to epigenetic changes. Conversely, the increased levels of MT observed in PBMCs from elderly subjects could be the physiological consequence of a stress response induced by inflammatory agents. A general pro-longevity role of MT emerges also from recent studies in mice. A longevity phenotype has been shown in MT transgenic mice that overexpresses the MT-1 isoform (MT1-tg) in the C57BL/ $6 \mathrm{~J}$ background (Malavolta et al. 2012), as well as in cardiac-specific MT transgenic mice that overexpress the human MT2 isoform in the FVB background (Yang et al. 2006). More recently, the findings that MT KO mice display a shortened life span can be considered a definitive proof that constitutive MT expression from birth to death may play a beneficial role in longevity, at least in mice, independently by the strain studied (Kadota et al. 2015). However, it is still uncertain if this situation may be comparable in humans and, most importantly, there are no examples of MT-inducible mice models, which might unravel the consequence of reactivation of MT expression in late life. Anyway, association studies of SNPs of MT genes point out a role of these proteins in human longevity or in the susceptibility to agerelated diseases but the functional role is far to be clarified (Giacconi et al. 2005; Cipriano et al. 2006). Taking inspiration from the role of MT in cancer, it should deserve appropriate consideration for future investigation the role of MT in cellular senescence. Currently, there is common agreement on the negative role of excessive accumulation of apoptosis-resistant senescent cells in aging and in several age-related diseases. This evidence is supported by the rejuvenating effects observed after inducible removal of senescent cells in transgenic animals (Baker et al. 2011, 2016) as well as after treatment of mice with senolytic drugs (Chang et al. 2016; Roos et al. 2016). While late passage senescent lymphocytes clones may display reduced expression of MT protein (Malavolta et al. 2008), some models of oncogene-induced senescence (Collado et al. 2005) and senescent endothelial cells (Malavolta et al. unpublished observation) appear to overexpress MT genes. In analogy with the role shown by MT in resistance to apoptosis of cancer cells, it might be possible to build the hypothesis that these proteins can play a role in the resistance to apoptosis of senescent cells. Investigation around this hypothesis might be important to optimize the development of senolytic drugs before human studies.

\section{Zinc Transporters, Immunosenescence, and Aging}

Increasing evidence suggest that zinc transporters play a major role in intracellular zinc homeostasis, which is critically involved in the signaling and activation of immune cells. While few gerontological studies have specifically addressed the role of zinc transporters, there is evidence that they may play a role in the process of progressive dysregulation of immune responses associated with aging.

A recent flow cytometry assay showed that uptake of extracellular zinc is reduced in PBMCs taken from elderly subjects compared to the younger counterpart (Giacconi et al. 2012). This observation argues for a possible downregulation of zinc importers' or upregulation of zinc exporters' function in aged immune cells. In 
agreement with this observation, a study performed in mice showed reduced Zip6 expression and dysregulation in splenocytes from aged mice (Wong et al. 2013). Most importantly, the age-specific Zip 6 dysregulation correlated with an increase in Zip6 promoter methylation while reduced Zip 6 expression was shown to enhance pro-inflammatory response. Similarly, a correlation between the level of methylation at SLC30A5 (ZnT5) promoter region and age has been reported in humans (Coneyworth et al. 2009). Moreover, methylation of the Znt5 promoter region resulted in reduction of ZnT5 expression and was hypothesized to contribute to the decline in $\mathrm{Zn}$ status observed with aging.

In addition to epigenetic changes occurring with aging, another potential link between immunosenescence and zinc transporters regards the regulation of Zip14 in the liver. Zip14 expression is upregulated through IL-6, and this mechanism was shown to be responsible of the hypozincemia that accompanies the acute-phase response to inflammation and infection (Liuzzi et al. 2005). Psychological stress, a putative recipe for accelerated aging, has been shown to induce zinc accumulation and upregulation of ZIP14 and metallothionein in rat liver (Tian et al. 2014). Since chronic inflammation, particularly driven by increased IL-6, is a usual event in old age (Mocchegiani et al. 2003), it cannot be excluded that this process may contribute to hypozincemia, depressed immune response, and risk of infection in the elderly.

However, it should be noted that a gene expression study on two major $\mathrm{Zn}$ transporters (ZnT1 and Zip1) in leukocytes obtained from two different age groups of Korean women indicated major changes following supplementation then baseline changes between the two groups (Andree et al. 2004). Hence, it is still uncertain which $\mathrm{Zn}$ transporters are more likely involved in age-related changes and, most importantly, which is the real impact of these changes on immune function and health of elderly subjects.

\section{Rationale for Zinc Supplementation in Aging}

\section{"In Vitro" Studies}

Since the discovery that the crude zinc balance is negative in old mice (Mocchegiani et al. 1995) and in old human (Turnlund et al. 1986), a number of studies involving zinc supplementation have been performed. Most of these studies have been focused on the effect of zinc on immune function, as "in vitro" experiments have provided considerable support on the immune-modulatory effects of zinc.

When PBMCs are stimulated with zinc, IL-1, IL-6, and TNF- $\alpha$, soluble (s)IL-2 receptor and IFN- $\gamma$ are released (Ibs and Rink 2003). The secretion of IL-1, IL-6, and TNF- $\alpha$ is induced directly by zinc in monocytes and is independent by the presence of lymphocytes (Driessen et al. 1994). However, the effect of zinc on monocytes may depend upon external stimulation. In fact, zinc inhibits LPS-induced TNF- $\alpha$ and IL-1 $\beta$ release from primary human monocytes and monocytic cell lines through the inhibition of cyclic nucleotide phosphodiesterase activity (von Bulow et al. 2005), suggesting that zinc may display also some anti-inflammatory properties. 
The dose of zinc used is also a critical variable. In serum-free culture medium, pharmacological concentrations ( $>100 \mu \mathrm{M}$ of zinc) stimulate monocytes but prevent $T$ cells from activating, perhaps due to the lower intracellular content in T cells than in monocytes (Ibs and Rink 2003).

Treatment with zinc "in vitro" generally displays also beneficial effects on cell survival but the effect largely depends upon the cell type and the dose of zinc used. The optimal concentration of zinc "in vitro" from genomic stability studies performed in different cellular models point out at concentrations in the range 4-16 $\mu \mathrm{M}$ (Sharif et al. 2011). It seems that both apoptosis prevention and induction are mediated by pathways involving zinc and/or zinc-dependent enzymes (Clegg et al. 2005; Wiseman et al. 2006). Therefore, the modulation of the zinc homeostasis plays a key role not only in preventing apoptosis, when oxidative stress is low, but also in inducing apoptosis, when oxidative stress and cellular damage is high. This mechanism could play a role, for example, in the elimination of virally infected or malignant cells (Fraker and Lill-Elghanian 2004). The pro-apoptotic function of zinc has been documented under condition of persistent oxidative damage in PBMC from young-adult humans as well as in very old age (Ostan et al. 2006). The key player that mediates the activity of zinc in this case appears to be the tumor suppressor $\mathrm{p} 53$, which needs zinc for site-specific DNA binding and proper transcriptional activation (Hainaut and Mann 2001; Loh 2010).

The response to zinc during stress condition appears be cell-type dependent. Experiments in thymocytes have shown that zinc from 50 up to $150 \mu \mathrm{M}$ prevents old thymocyte apoptosis induced by dexamethasone or serum deprivation (Provinciali et al. 1998), whereas the direct introduction of free zinc as zincpyrithione inside thymocytes induces apoptosis (Mann and Fraker 2005). It is likely that the continuous presence of intracellular free zinc ions induced by Zn-pyrithione can be interpreted by the cell as a presence of irreversible damage with subsequent activation of pro-apoptotic pathways.

\section{Animal Studies}

Old literature documented that zinc supplementation performed throughout the whole life span of rodents is able to delay some age-related cell-mediated immune modifications, such as the decreased circulating thymic hormone levels (Iwata et al. 1979). However, an immunomodulatory effect of $\mathrm{Zn}$ supplementation has been shown with a relatively short time of treatment in old mice. For example, $18 \mu \mathrm{g} / \mathrm{ml}$ $\mathrm{Zn}^{++}$in the drinking water induced thymus regrowth and functionality (Dardenne et al. 1993; Mocchegiani et al. 1995) as well restoration of NK cell cytotoxicity (Mocchegiani et al. 1995) in old mice in just 1 month. That the benefit of zinc supplementation upon the immune functions in old mice is not to consider an epiphenomenon comes by the analysis of the rate of survival in old zinc-treated mice. Old mice (inbreed Balb/c mice) treated with daily zinc at the dose reported above in drinking water from the pre-senescent age (12-14 months of age) display a significant increment of the median and maximal life span (up to 33 months vs. 28-29 of controls) (Mocchegiani et al. 2000b). The increased longevity was largely due to significant decrements of deaths due to cancer and infection in the 
middle age. Part of the effects shown in aged mice can be the consequence of an improved thymopoiesis (Wong et al. 2009). However, increased longevity after zinc supplementation was also reported in the short lived thymectomized and nude mice, which display a negative crude balance of zinc (Mocchegiani et al. 2007). Taking into account that the liver extrathymic $\mathrm{T}$ cell pathway is prominent in nude, thymectomized and old mice (Abo et al. 2000), it is likely that these effects of zinc may be in part the effects of zinc on this extrathymic pathway (Mocchegiani et al. 1998). Conversely, in aged C57Bl/6 mice, zinc supplementation $(300 \mathrm{mg} / \mathrm{kg}$ for 25 days) was shown to increase thymopoiesis, as assessed by increased total thymocyte numbers (Wong et al. 2009). The improved thymic output was mediated in part by reducing the age-related accumulation of immature CD4(-)CD8(-)CD44 $(+) \mathrm{CD} 25(-)$ thymocytes, as well as by decreasing the expression of the thymosuppressive cytokine named stem cell factor. A slightly increased survival has been also recently documented in old (age $\geq 17$ months) C57BL/6 J mice supplemented for the whole life span with $380 \mathrm{mg} / \mathrm{L}$ of zinc in drinking water. However, survival curves of supplemented mice displayed an increased variability and were markedly lower compared to those of transgenic mice overexpressing MT independently of zinc supplementation (Malavolta et al. 2012). The results of mice overexpressing MT are similar to those obtained in worms with zinc chelation (Kumar et al. 2016). These data may reinforce the idea that zinc has a potential antagonistic pleiotropic. In particular, zinc may act on nutrient-sensing pathways (e.g., insulin/IGF-1-like receptor pathway and $\mathrm{PI} 3 \mathrm{~K} / \mathrm{AKT} / \mathrm{mTOR}$ pathway) with the final result of promoting growth and proliferation. Inhibition of this pathway has been proposed as a pro-longevity treatment while its enhancement may help elderly, which in turn display excessive downregulation of nutrient-sensing pathways as a consequence of compensatory phenomena normally occurring in aging. This point of view could explain the beneficial effects observed by supplementation in elderly and old mice.

\section{Human Studies}

With regard to elderly, there is consistent support that zinc supplementation may slightly impact immune system, but real benefits appears to be evident only in the case of well-documented nutritional zinc deficiency. An exhaustive picture of the zinc supplementation in elderly by different studies has been reported by Haase and Rink (2009). Many attempts have been performed in the past using different doses of $\mathrm{Zn}$ for various treatment duration (Duchateau et al. 1981; Sandstead et al. 1982; Bogden et al. 1990; Prasad et al. 1993; Boukaïba et al. 1993; Cakman et al. 1997; Fortes et al. 1998). Immunostimulative effects of zinc have been documented using pharmacological doses largely exceeding the RDA. For example, Duchateau et al. (1981) and Sandstaed et al. (1982) reported an improvement in response to skin-test antigens and taste acuity with doses of zinc around $220 \mathrm{mg} /$ day for 1 month.

However, in the majority of the studies, zinc supplements were used in the range proposed by the RDA while attempting to not exceed the tolerable upper intake level (usually a range from 8 to $25 \mathrm{mg} /$ day). Prasad et al. (1993) and Boukaniba et al. (1993) have found an increment of thymulin activity and improvements in response to skin-test antigens and taste acuity (zinc dose $=15 \mathrm{mg}$ /day for 4 months); Bodgen 
et al. (1990) have reported no benefit exclusively for increased lymphocyte mitogen proliferative response (zinc dose $=15 \mathrm{mg}$ /day for 1 year); Cakman et al. (1997) have found enhanced IFN- $\gamma$ production by leukocytes (zinc dose $=15 \mathrm{mg}$ /day for 45 days); Fortes et al. (1997) report an increased number of cytotoxic T lymphocytes (zinc dose $=25 \mathrm{mg}$ /day for 40 days). A long-term (6 months) supplementation trial with two doses of zinc (15 and $30 \mathrm{mg} /$ day) in elderly was recently conducted by the Zenith study (Hodkinson et al. 2007). Zn supplementation of $30 \mathrm{mg} /$ day significantly lowered B-lymphocyte at month 3 but not later. Zn supplementation of $15 \mathrm{mg} /$ day significantly increased the ratio of CD4 to CD8 T lymphocytes at month 6. Overall, these findings suggest $\mathrm{Zn}$ supplementation has minimal longterm effects on immune status of healthy elderly persons. In the framework of a recent European study focused in zinc and immunosenescence, elderly subjects to be supplemented with zinc were chosen according to the presence of a pro-inflammatory genotype for IL-6 and low plasma zinc (Mocchegiani et al. 2008). Supplementation (with $10 \mathrm{mg} /$ day of $\mathrm{Zn}$-aspartate for $48+/-2$ days) was carried out in 110 old subjects (age $>65$ years) who presented stable low plasma zinc levels $(\leq 10.5 \mu \mathrm{M}$ at baseline and at 1 year follow-up) and in C-carriers for IL-6 $-174 \mathrm{G} / \mathrm{C}$ with unstable plasma zinc $(\leq 10.5 \mu \mathrm{M}$ at baseline and $>10.5 \mu \mathrm{M}$ at 1 year follow-up). Most evident effects of zinc supplementation on immune system comprised both corrective, but also noncorrective effects on known immunosenescence markers, including: (1) an improved susceptibility of $\mathrm{T}$ cells to activation-induced cell death (AICD) (Varin et al. 2008); (2) an increased circulating levels of IL-6, MCP-1 associated with increased NK activity that were partly dependent on IL-6 $-174 \mathrm{G} / \mathrm{C}$ and +647 MT1a SNPs (Mariani et al. 2008); (3) an increase of TH1 and $\mathrm{TH} 2$ cells in thawed samples and a slight reduction in TH2/TH1 ratio in fresh whole blood lymphocytes (Uciechowski et al. 2008); (4) a marked increase in both basal as well as stress-induced Hsp70 levels in lymphocytes from healthy elderly donors with a higher impact on CD3+ cells (Putics et al. 2008); and (5) reduced spontaneous cytokine release in PBMCs and defects in termination of inflammatory activity (Kahmann et al. 2008). In the same population, Giacconi et al. (2015) studied the influence of ZIP2 Gln/Arg/Leu (rs2234632) polymorphism on zinc homeostasis and inflammatory response following zinc supplementation. Leu- (Arg43Arg genotype) elderly showed higher inflammatory markers at baseline than carriers of other alleles that were reduced after zinc supplementation.

Later, the influence of +1245 A/G MT1A SNP on plasma AGEs and ROS production by PBMCs at baseline and after zinc supplementation was also studied (Giacconi et al. 2014). +1245 G+ carriers showed increased plasma AGEs and ROS production in PBMCs at baseline with a significant interaction of genotype on zinc supplementation only in limited markers of intracellular zinc status.

More recently, a randomized, double-blind, placebo-controlled study (with $30 \mathrm{mg}$ $\mathrm{Zn}$ /day) has been performed on $n=16$ nursing home elderly (aged $\geq 65$ year;) with low serum zinc concentration (serum zinc $<70 \mu \mathrm{g} / \mathrm{dL}$ ) versus $n=15$ placebo ( $5 \mathrm{mg} \mathrm{Zn/day)}$ group. In this case, the treatment group showed an increase in serum zinc concentration that was associated with an increase in the number of T cells (Barnett et al. 2016). 
It is also noteworthy to mention the effects of a Zinc fortified milk (designed to integrate $4 \mathrm{mg}$ zinc/day for 2 months) on the cytokine production of PBMCs obtained from very old subjects (age $>81$ years). In unstimulated PBMCs from these subjects a significant percent change $(p<0.05$ or $p<0.01)$ of cytokine release is evident and is related to a good functioning of the cell-mediated immunity $(63.9 \%$ IL-12p70 and $29.72 \%$ IFN- $\gamma$ ) coupled with increase of anti-inflammatory cytokines (43.54\% IL-10) and decrease of pro-inflammatory cytokines $(27.08 \%$ IL- $1 \alpha)$ (Costarelli et al. 2014).

Thus, it seems evident from these studies that physiological dose of zinc for a long period or high doses of zinc for short periods might induce limited effects on immune response.

Although the body of proof of an impact of zinc on immunosenescence is consistent, there is limited knowledge on the long-term effects and outcome (e.g., protection from infection) of zinc supplementation in elderly. Current evidence suggests that benefits on immune response and health outcome are likely to be obtained with doses around the RDA in elderly with documented zinc deficiency. Unfortunately, we do not have in this moment a reliable assessment of zinc status that can undoubtedly identify subjects with zinc deficiency. Taking into account this lack of knowledge, it is recommended to educate elderly to consume an appropriate diet with foods that contain the necessary zinc requirements.

\section{Zinc Interaction with Other Micronutrients and Zinc Toxicity}

The effect of zinc supplementation may be related to the levels of other cations such as cadmium, lead, calcium, iron, manganese, and copper. The beneficial effects of zinc on ameliorating toxicity of cadmium and lead, the accentuation of zinc deficiency by administration of calcium and phytate, and production of hypocupremia by excessive zinc intake in humans and animals are some examples of competition phenomena between these cations (Hill 1976). Such a competition occurs because these ions have similar valence shell electronic structure and therefore could be antagonist to each other. For instance, the competition between zinc and iron $(\mathrm{Fe}++)$ occurs at the level of cysteine-histidine ligands for the formation of iron or zinc "fingers" proteins (Prasad 1993). If iron is in excess, a preferential binding of iron than zinc to the metal free-protein occurs. Excess of zinc or zinc deficiency impairs DNA-protein interactions of zinc fingers domains with their cognate DNA target sites. In these conditions the production of some transcriptional factors like SP1 or TFIIIA is altered (Thiesen and Bach 1991). Similar transcriptional alterations occur in excess or deficiency of copper (Prasad 1993). This reinforces the notion of the relevance of interactions between zinc and copper as well as with other metals in the immune efficiency (Sandstead 1995). In order to avoid interference with copper homeostasis, it has been proposed to not exceed 2-3 times the RDA with zinc supplementation and to perform alternate cycles of supplementation not longer than 1-2 months (Licastro et al. 1994; Feillet-Coudray et al. 2006). 
Combination of zinc in complex micronutrient supplements appears to produce minimal and contrasting effects. Health status was recently investigated in older French adults 5 years after a period of daily nutritional-dose supplementation with antioxidant nutrients (Assmann et al. 2015). During 1994-2002, participants received a daily combination of vitamin $\mathrm{C}(120 \mathrm{mg}), \beta$-carotene $(6 \mathrm{mg})$, vitamin $\mathrm{E}$ $(30 \mathrm{mg})$, selenium $(100 \mu \mathrm{g})$, and zinc $(20 \mathrm{mg})$ or placebo. Healthy aging was assessed in 2007-2009 with multiple criteria (e.g., absence of major chronic disease and good physical and cognitive functioning). Supplementation was associated with a slightly greater healthy aging probability among men, but not among women or all. Similarly, another study assessing a micronutrient mix (288 mg vitamin E, $375 \mathrm{mg}$ vitamin C, $12 \mathrm{mg}$ beta-carotene, and $15 \mathrm{mg}$ zinc/day for 10 weeks) on immune function parameters of a population of subject aged 40-80 years showed only an increase of delayed-type hypersensitivity (DTH) responses (in particularly in the oldest subjects) without any change in responses to systemic tetanus and oral typhoid vaccination, phagocytosis, oxidative burst, lymphocyte proliferation, and lymphocyte subset distribution (Wolvers et al. 2006).

Importantly, vitamin and mineral supplements (including zinc) in older women were found to be associated with increased total mortality risk compared with nonusers in other studies (Bjelakovic and Gluud 2011; Mursu et al. 2011). These results reinforce the idea that nutritional guidelines instead of supplementation might be the preferred choice, while keeping interventions with micronutrients only for short periods in case of documented deficiencies.

\section{Selenium}

\section{Selenium Biology and Homeostasis}

Selenium is considered since long time ago an essential dietary element for the prevention of some diseases, including cancer and infections (Schwarz 1976). In food, selenium derives from vegetables and animal products and in particular from the consumption of seafood, liver, and cereals. However, in vegetables and cereals the amount of selenium varies in soil in different countries and geographical regions (Wasowicz et al. 2003). Indeed, selenium deficiency and related diseases have been well documented in geographic regions where the soil content is low, such as the Chinese province of Keshan ( $\mathrm{Li}$ et al. 1985). From this region of China, in fact, was taken the name of the Keshan disease, a pathology characterized by selenium deficiency and the presence of mutated strains of coxsackievirus (Li et al. 1995).

Mammals can use both inorganic and organic selenium as a nutrient. Most of the biological functions of selenium are attributed to selenoproteins, which contain selenocysteine residues responsible for their specific activity. Selenoproteins are present in every cell type. The human selenoproteome consists of 25 selenoproteins, mostly involved in antioxidant defense systems (Kryukov et al. 2003).

Glutathione peroxidases (GPxs), a family of the selenoproteins, protect cells against oxidative damage by catalyzing the reduction of hydrogen peroxide and 
other hydroperoxides (Hall et al. 1998; Brigelius-Flohé 1999). Five seleniumdependent GPx isoforms exist in humans and four isoforms in mice. GPx1 is found in the cytosol of almost all cells and catalyzes the reduction of free hydroperoxides. GPx2 is expressed in the gastrointestinal tract and has a substrate specificity similar to GPx1; GPx3 is an extracellular enzyme found in plasma and reduces membrane-bound phospholipid hydroperoxides (Brigelius-Flohé 1999). GPx4 is expressed in various tissues, and reduces phospholipid hydroperoxide and hydrogen peroxide using also thiols, such as 2-mercaptoethanol, cysteine, and homocysteine, other than GSH as reductant agents (Roveri et al. 1994). The isoform GPx6 seems to be specifically expressed in embryonic tissues and olfactory epithelium (Kryukov et al. 2003). It also exists as a selenium-independent isoform, GPx5, which is an epididymis isoenzyme present in mice and humans (Hall et al. 1998), but its mRNA was found to be not translated into functional protein in human epididymis (Ghyselinck et al. 1993). Selenium is also involved in the thioredoxin system, a major enzymatic system that plays an important role in maintaining the redox state of the cell (Holmgren 1985). This system is highly complementary to the GSH system in protecting against oxidative stress (Watson et al. 2004). It comprises basically of thioredoxin (Trx) and the selenoprotein thioredoxin reductase (TR) and uses the reducing power of NADPH to act as a potent antioxidant system as well as a general disulfide redox system (Rundlof and Arner 2004). Mammalian TR maintains Trx in a reduced state (Holmgren 1985) and reduces a variety of other substrates including nondisulfides. The thioredoxin system protects the cell against oxidative stress through a variety of mechanisms. Trx can directly quench single oxygen and scavenge hydroxyl radicals (Das and Das 2000), or reduced Trx can indirectly serve as an electron donor for Trx peroxidase. In addition, human TR is directly capable to efficiently reduce lipid hydroperoxides, hydrogen peroxide, and organic hydroperoxides using NADPH, especially in the presence of catalytic amount of selenocysteine, thus serving as an important alternative to the Gpx pathway for the elimination of harmful hydroperoxides (Björnstedt et al. 1995). Trx system is also critical for signal transduction (Arner and Holmgren 2000) and in the restoration of the reduced form of several antioxidant compounds, including ascorbic acid, lipoic acid, and ubiquinone (Nordberg and Arner 2001). In this context, selenomethionine, a potent catalytic antioxidant in biological system and an aminoacid occurring in proteins in place of methionine (Walter and Roy 1971), reacts more efficiently than methionine (Padmaja et al. 1996) with oxidants forming methionine selenoxide which, in turn, is effectively and rapidly reduced to seleniomethionine by glutathione (Assmann et al. 1998). In contrast, methionine sulfoxide, which is produced by the oxidation of methionine in presence of oxidants, is not simply reduced by GSH, but it requires a specific enzymatic reaction catalyzed by methionine sulfoxide reductase (Levine et al. 1996). Since selenomethionine can occur in proteins such as hemoglobin (Beilstein and Whanger 1986), these residues may play a defensive role against peroxinitite.

Another selenoprotein, which reduces phospholipid hydroperoxides in the presence of thiols, is the Selenoprotein P (SeP) (Burk et al. 2003). SeP is expressed in many tissues and represents the major plasma selenoprotein, which contains $50 \%$ of 
the total plasma selenium in the form of selenocysteine. SeP protects endothelial cells against damage from peroxynitrite and transports selenium from the liver to peripheral tissues.

Last, but not the least in order of importance, is a class of selenoproteins (iodothyronine deiodinase enzymes), which catalyze the peripheral deiodination of thyroxin (T4) to 3,3'5-triiodothyronine (T3). These enzymes play crucial roles in determining the circulating and intracellular levels of T3 and, consequently, the control of growth, development, differentiation, metabolism, and finally also the immune response (Kohrle 2000; Beckett and Arthur 2005).

Immunologically, the ability of selenoproteins to protect the host from oxidative stress is vitally important, as many host defense systems rely on the microbiocidal effects of macrophage- or neutrophil-generated free-radical species. Oxidative species are generated through general metabolism, during the metabolism of xenobiotics and during exposure to ultraviolet radiation (UV) in sunlight. Inflammation as a process to clear infection and damaged tissue also generates great oxidative stress. If antioxidant systems are not functioning correctly, host cells will be damaged (McKenzie et al. 1998). Taking into account that chronic inflammation and oxidative stress are features of aging (Franceschi et al. 2000), it is likely that Se mediates protective effects through upregulating the antioxidant defenses and host immune responses.

\section{Selenium Homeostasis, Immunosenescence, and Aging}

The influence of selenium on the immune function can be, in part, attributed to the same selenoproteins involved in the protection against oxidative damage and, in part, to still undefined biochemical pathways. The antioxidant GPxs have probably a role in protecting neutrophils from ROS that are produced during inflammation (Arthur et al. 2003; Arthur 2003). Selenium supplementation, in mice, increases the expression of subunits alpha (p55) and/or beta (p70/75) of IL-2 receptor (IL-2R) from activated lymphocytes and NK cells, thereby enhancing proliferation and clone expansion of cytotoxic precursor cells. In vitro, selenium enhances the release of tumor necrosis factor (TNF), IL-1, and IL-6 from LPS-stimulated macrophages (Beckett et al. 2004). However, one of the most widely investigated associations between selenium and the immune system is the effect of the micronutrient on neutrophil function. Neutrophils produce superoxide-derived radicals to take part in killing of microbes. This type of process is a balance between the production of sufficient radicals to kill invading organisms and the systems that protect the neutrophils themselves from the radicals. Thus, although selenium deficiency does not seem to affect neutrophil number, certain aspects of their function are defective (Turner and Finch 1991). Neutrophils from selenium-deficient mice, rats, and cattle are able to ingest pathogens in vitro but are less able to kill them than are neutrophils from selenium-sufficient animals. This defective function has been associated with decreased cytosolic GPx (GPx1) activity in the neutrophils, which allows the free radicals that are produced in the respiratory burst to kill the neutrophils themselves (Arthur et al. 2003). 
This is the reason why selenium deficiency may involve oxidative damage of biomolecules, such as lipids, lipoproteins, and DNA, that is well known to play a role in many age-related diseases.

Anyway, selenium deficiency is a condition mainly attributed to geographical factors that include a low selenium content in the soil or to long-term parenteral nutrition rather than aging itself. Selenium levels in blood have been studied in different age-related diseases such as cancer, cardiovascular disease, and immune dysfunctions. Additionally, as for many other micronutrients, Se inadequacy likely due to malnutrition or intestinal malabsorption may occur in older people (Seiler 2001). However, few data reported a marked selenium deficiency in old subjects. In the baseline results of the SU.VI.M.AX study (involving 7876 women aged 35-60 and 5141 men aged $45-60$ ), it was reported that fewer than $2 \%$ of the volunteers had a serum Se status under $0.75 \mu \mathrm{M}$, which has been proposed as the threshold for Se sub-deficiency and that age was associated with increased serum Se concentrations in women (Arnaud et al. 2006). However, in the same study, large part of the population displayed a value of blood selenium below the range of levels $(1.0-1.2 \mu \mathrm{M})$ proposed as optimal for GPx and selenoprotein P (Combs 2001; Thomson 2004). In the EVA (Etude du Vieillissement Artériel) study, a longitudinal study that explored the relationships between plasma selenium and mortality in an elderly population for over 9 years, mortality rates were significantly higher in individuals with low selenium [increments $=0.2 \mu \mathrm{M}$; relative risk $(\mathrm{RR})=1.56$; $95 \% \mathrm{CI}=1.28-1.89$ ] (Akbaraly et al. 2005). When the underlying causes of death were considered, an association with low selenium and cancer-related mortality was found. The same authors suggest that plasma selenium could be an indicator of longevity in the pre-aging period of life. Survival curves illustrate that the relationship between plasma selenium and mortality remained pertinent during the entire 9-year period (Akbaraly et al. 2005). However, the mechanism of this potential relationship is still unclear. Other authors observed selenium deficiency in elderly people in relation to hypothyroidism (Olivieri et al. 1996). Interestingly, most of human healthy centenarians seem to display selenium values equal or greater than the lowest values reported in normal elderly (Savarino et al. 2001).

The relevance of selenium in the etiology of cardiovascular diseases has been also extensively studied. Selenium metabolism is potentially involved in several protective biochemical pathways related to cardiovascular disease, such as reduction of LDL levels and lipoprotein oxidation, inhibition of foam-cell formation, and shift in prostaglandin production from prostacyclin to tromboxane (Alissa et al. 2003). However, Wei et al. (2004) found no association between death for cardiovascular diseases and baseline selenium status in a cohort of adult individuals (mean age, 57 years) with a mean serum concentration of $0.93 \mu \mathrm{M}$.

Finally, an intriguing point is the association between selenium deficiency, immune response, and increased incidence of infections in adults and elderly. In a prospective study performed in patients with systemic inflammatory response syndrome, a $40 \%$ decrease in plasma selenium concentrations was observed compared to reference range (Forceville et al. 1998). Moreover, low levels of selenium in these patients were associated to morbidity and mortality while survivors at follow-up 
displayed slightly increased selenium levels. The interrelationships between selenium deficiency, impaired immune response, and infections have been clearly shown in experimental animals. An inoculated avirulent virus in selenium-deficient animals turns into a virulent one due to genomic changes within the virus, provoking an impaired humoral immune defense (Beck 1999).

An enhanced oxidative stress, caused by selenium deficiency, is the likely reason of possible viral genetic changes (Beck et al. 2003) and increased progression of viral infections with subsequent impaired immune defense (Daniels 2004).

Regarding the role played by selenium deficiency in viral infections it is also noteworthy to mention the: (i) the emergence of newly recognized human disease agent (coronavirus) that causes SARS from Guangdong Province of China (Lashley 2006) as well as from Northern Vietnam (Reynolds et al. 2006), where significant areas of overt selenium deficiency exist (Xia et al. 2005) and (ii) the increased risk of enhanced virulence of influenza virus in elderly (Ellis et al. 2003) associated with a possible selenium deficiency (Seiler 2001). Therefore, selenium deficiency may be considered a risk factor for age-related diseases (cancer, cardiovascular diseases, and infections). Such a risk is of relevance in elderly because accumulating data suggest that persistent infection with Varicella-zoster virus (VZV) (Arvin 1996), EpsteinBarr virus (EBV) (Stowe et al. 2007), and particularly CMV (McVoy and Adler 1989) impacts upon the immune system in aging and may contribute to the immune risk phenotype (IRP), which predicts remaining longevity in the very elderly (Pawelec et al. 2005). Specific study on these aspects should be encouraged taking into account the possible relevant implications for public health.

\section{Rationale for Selenium Supplementation}

\section{In Vitro Studies}

Cellular studies with selenium provide evidence that, in analogy with zinc, it may have anticarcinogenic and antioxidant effects at low concentrations, whereas at concentrations higher than those necessary for nutrition, it can be genotoxic and carcinogenic (Valdiglesias et al. 2010). Se toxicity "in vitro" depends primarily on Se compound and dose but also on exposure time and cellular model. Conversely to the reputation of an antioxidant and protective trace element, various "in vitro" studies found that Se compounds can induce DNA damage (Biswas et al. 2000; Machado et al. 2009) and produce oxidative stress (Wycherly et al. 2004). An investigation on chromosome breaking activity of various Se compounds demonstrated that all may induce this kind of damage with an efficacy that follows this order: selenious acid $>$ sodium selenite $>$ Se dioxide $>$ selenic acid $>$ sodium selenite (Nakamuro et al. 1976). As a consequence, it is not surprising that selenocompounds (mainly sodium selenite but also SeMet, Se dioxide, and methylseleninic acid) induce cell death in various mammalian cell lines (Valdiglesias et al. 2010).

An intensive investigation on apoptosis-inducing effects of organic selenium derivatives showed that breast carcinoma cells were highly sensitive to the organic selenium compounds, manifesting apoptosis at $0.113 \mu \mathrm{M}$ of selenium while 
nontumorigenic mammary epithelial cells required concentration above $80 \mu \mathrm{M}$. Cell lines derived from hepatoma and neuroblastoma showed intermediate sensitivity and colon carcinoma cells were more resistant to selenium-induced apoptosis (Jariwalla et al. 2009).

A role for Se in DNA repair has been also documented, likely as a consequence of its modulatory activity on Nrf2 pathway both in tumor and normal tissues (Zhang et al. 2008). However, the concentrations of selenium compounds, in combination with the medium components and the biological physiology of the cell, affect the redox potential of the compounds that may switch from pro-oxidant to antioxidant (Cemeli et al. 2006). A recent paper investigated the ability of selenium supplementation in vitro (in the form of $\mathrm{Na}_{2} \mathrm{SeO}_{3} 100 \mathrm{nM}$ or $200 \mathrm{nM}$ ) to modify monocyte cell viability and ROS production under condition of oxidative stress (induced by Paraquat $100 \mathrm{mM}$ and S-Nitroso- $N$-acetyl-DL-penicillamine $10 \mathrm{mM}$ ) (Leighton et al. 2015). The experiments indicated that selenium supplementation, especially with the lower dose tested, was effective in improving cell viability and ROS quenching ability of monocytes. A previous study addressing the influence of selenium supplementation "in vitro" on macrophages reported enhanced phagocytosis, degranulation, and production of superoxide anion after phorbol myristate (Safir et al. 2003).

In general, it is not easy to give an interpretation of the results "in vitro," especially when addressed at generation of ROS and immune function. Indeed, ROS are not only used to kill pathogens, but they have been recently recognized as important mediators of cell signaling and cell to cell communication in phagocytic and nonphagocytic immune cells (Zhang et al. 2016). So, even if we know that Se compounds in vitro may affect ROS production and phagocyte function (Huang et al. 2012), the overall rationale for supplementation strategies can only derive from "in vivo" supplementation studies. Furthermore, there is evidence that as in the case of zinc the expression of several selenoproteins involved in antioxidant defense is specifically affected in response to cellular senescence (Yona et al. 2014; Malavolta et al. 2014; Provinciali et al. 2016). Taking into account that senescent cells accumulate with aging and that cellular senescence is a phenomenon that displays antagonistic pleiotropic effects (Campisi 2014) on physiological and pathological processes, it is likely that many changes observed with aging and attributed to changes in selenium status involve the process of cellular senescence and that their impact on overall health are rather difficult to be correctly predicted.

\section{Animal Studies}

Multiple experimental studies in animal models have revealed that Se-deficiency impairs immune response to infection, cancer, and other stimuli. For example, Se deficiency was reported to reduce $\mathrm{CD} 4+\mathrm{T}$ cell response in mice challenged with a peptide/adjuvant (Hoffmann et al. 2010), to increase tumor growth and burden in a breast cancer mouse model (Chen et al. 2013), to increase type I allergic response in a mouse model of cutaneous anaphylaxis (Arakawa et al. 2013), and to increase immunotoxicity of arsenic (Rodríguez-Sosa et al. 2013). The IL-6 and interferon- $\gamma$ pathways appear to be among the pathway more responsive to dietary selenium intake in mice (Tsuji et al. 2015). Although excessive releases of IL-6 and interferon- 
$\gamma$ have been associated with inflamaging, moderate increases and adequate response of these cytokines are known play a pivotal role in host defense through the ability to activate macrophage cell functions thus contributing to keep under control infectious diseases. Decreased dietary selenium can change a normally avirulent B3 coxsackievirus (CBV3/0) into a virulent virus (CBV3/20) by inducing changes in viral genoma, especially in viral RNA polymerase (Duarte et al. 1994). The mutated virus can infect heart muscle and cause myocarditis with the likely development of dilated cardiomyopathy and death (Beck and Levander 2000; Jun et al. 2011). Similar to the data reported for Coxsackie virus, selenium intake and selenium status affected the host immune response, the mutation rate of the viral genome, and the pathology in mice infected with the human influenza A/Bangkok/1/79 (H3N2) virus (Nelson et al. 2001). However, the impact of selenium status on the outcome of the immune response appears to depend on the virulence of the applied influenza A virus strain. Indeed, opposite results with an increased mortality of the selenium adequate group were observed using a the influenza $\mathrm{A} /$ Puerto Rico/8/34 virus, which is highly pathogenic in mice (Li and Beck 2007).

With regard to cancer, many studies have investigated the effects of selenium in carcinogen-exposed animals showing a reduction in tumor incidence and/or pre-neoplastic endpoints (Reid et al. 2002). Various animal experiments have been conducted by combining experimental selenium deficiency with treatment with carcinogens, such as 1,2-dimethylhydrazine (DMH) or dimethylbenz(a)anthracene (DMBA), and comparing the results with animals fed with higher content of selenium in the diet. In general, Se deficiency appears to affect DMH toxicity with, however, no inhibition of tumor development by nutritional Se $(0.1 \mathrm{ppm} \mathrm{Se})$ (Pence and Buddingh 1985). Three relevant papers report a greater development of carcinoma by DHM or DMBA in various organs (colon and mammary gland) of rats under selenium deficiency in comparison with rats treated with 5 ppm of Se (Jacobs 1983; Liu and Milner 1992; McGarrity and Peiffer 1993). These findings further suggest the ability of dietary selenium to inhibit the in vivo metabolism of carcinogens DMBA or DMH and, consequently, to inhibit the development of the tumor.

Selenium supplementation in old mice was also shown to counteract immunosenescence (Roy et al. 1995). In C57BL/6JNIA mice aged 24 months, supplementation with selenium ( $2.00 \mathrm{ppm}$ as sodium selenite for 8 weeks) corrected age-related defect in lymphocyte proliferation likely as a consequence of an increased number of high-affinity IL-2 receptors.

\section{Human Studies}

Unfortunately, few trials have been carried out up in elderly with a clear focus on immunosenescence. Although selenium supplementation improved lymphocyte mitogen responsiveness of institutionalized elderly individuals (Peretz et al. 1991), it is difficult to conclude on a specific beneficial effect of selenium in immunosenescence. A Finnish study adding selenium to fertilizer has shown only an increased selenium status in the general population (young, adult, old) (Aro et al. 1995) without any clear beneficial effect on general health. A recent randomized, doubleblinded, placebo-controlled clinical trial was undertaken to test the effects of Se 
supplementation on a variety of parameters of anti-flu immunity in healthy subjects aged 50-64 years (Ivory et al. 2015). The authors used six doses of Se (in different form from 0 to $200 \mu \mathrm{g}$ /day) for 12 weeks in six groups of individuals with plasma Se levels $<110 \mathrm{ng} / \mathrm{mL}$ who received Flu vaccine (at week 10). In this trial, Se supplementation resulted in both beneficial and detrimental effects on cellular immunity to flu that was affected by the form of Se, supplemental dose and delivery matrix. In general, the dose-dependent increase in T cell proliferation, IL-8 and IL-10 secretion after in vivo flu challenge were contrasted by lower granzyme B content of CD8 cells or by inhibition of TNF- $\alpha$ synthesis.

Another recent study was conducted to evaluate the effects of selenium supplementation $(200 \mu \mathrm{g}$ selenium supplements for 8 weeks) on metabolic profiles, biomarkers of inflammation, and oxidative stress of patients with type 2 diabetes and coronary artery disease aged $40-85$ years (Farrokhian et al. 2016). Supplemented patients displayed a significant decrease in insulin, homeostasis model of assessment-insulin resistance, homeostatic model assessment-beta cell function, serum hs-CRP, and a significant increase in quantitative insulin sensitivity check index score and plasma total antioxidant capacity concentrations. The positive impact on these biomarkers is, unfortunately, not complemented by a long-term follow-up. However, reduced cardiovascular mortality at 10 -years follow-up was observed in another supplementation trial performed on 443 elderly with selenium and coenzyme Q10 (Alehagen et al. 2015). In agreement with the protective role of selenium a Sweden study performed in 668 elderly subjects showed that persons with serum Se in the lowest quartile had $43 \%$ and $56 \%$ increased risk for all-cause and cardiovascular mortality, respectively (Alehagen et al. 2016). This confirms the reduced incidence of cardiovascular diseases observed in previous studies after supplementation with selenium combined in multivitamins supplements (Czernichow et al. 2005; Shenoy et al. 2006). There is also evidence that a number of HIV-positive patients suffer from deficiencies in vitamins including selenium (Coodley 1995). Enhanced GPx and GSH activity (Delmas-Beauvieux et al. 1996) were observed in HIV patients receiving oral selenium supplementation. This finding suggests that GPx and GSH activity may represent natural inhibitors of (AIDS) viruses and that selenium supplementation may play a role in prevention antiviral strategies (Rayman 2000). Of interest, supplementation with multivitamins and trace elements, including Se, during treatment of pulmonary Tuberculosis reduced mortality in subjects co-infected with HIV (Range et al. 2006).

Large part of the other studies involving selenium supplementation in humans have been conducted in adult subjects with the aim to prevent or counteract various type of cancer.

Past studies showed that supplementation with $200 \mu \mathrm{g}$ /day of organic selenium in randomized subjects showed preventive effects in the incidence and the mortality from various types of cancer (prostate, colorectal, and lung cancer) (Clark et al. 1998). Another large supplementation trial with lower amount of selenium $(50 \mu \mathrm{g})$ performed in Lixian (North China) showed a small but significant reduction in total and cancer mortality was observed in subjects receiving selenium supplement (Blot et al. 1995). The impact of Se supplementation was better in women than men and, 
interestingly, the effects were more pronounced in persons under the age of 55 years compared to individuals older than 55 years. Moreover, supplementation with $200 \mathrm{mg} /$ day of sodium selenite during therapy of patients with squamous cell carcinoma of the head and neck resulted in a significantly enhanced cell-mediated immune responsiveness (better response of lymphocytes to stimulation with mitogen, generation of cytotoxic lymphocytes, and destruction of tumor cells) (Kiremidjian-Schumacher et al. 2000). Considering these results, it might be assumed that younger persons might be more amenable to a protective effect of selenium supplementation. However, a recent large Selenium and Vitamin E Cancer Prevention Trial (SELECT) carried out in North America has reported unexpected and very concerning findings, especially the increased the risk of high-grade prostate cancer among men with high selenium status (Kristal et al. 2014). Perhaps, the most conclusive data regarding the story of selenium and cancer can be retrieved from an excellent systematic review that included 55 prospective observational studies as well as 8 randomized clinical trials (Vinceti et al. 2014). The authors of this systematic review concluded that the inverse association between selenium exposure and the risk of some types of cancer cannot be taken as evidence of a causal relation, and that all these studies have many limitations, including issues with the form and the assessment of selenium, heterogeneity, confounding and other biases. Moreover, randomized clinical trials reported inverse, null, and direct associations have been reported for some cancer types which overall yielded inconsistent results with even harmful effects of selenium exposure. Hence, to date, no convincing evidence suggests that selenium supplements can prevent cancer in humans.

\section{Interrelationship Between Zinc and Selenium: Implications for Healthy Aging}

Dietary zinc and selenium are important nutritional factors for the immune response in protecting against the appearance of age-related diseases. There is a number of biochemical processes in which selenium and zinc interact. Selenium compounds that have the capacity to form selenol(ate)s catalytically couple with the glutathione/ glutathione disulfide and metallothionein/thionein redox pairs to either release or bind zinc. (Maret 2003). When MT are oxidized by glutathion disulfide (GSSG) or other disulfides free zinc is released in the cytosol. However, the efficiency of this chemical reaction seems very low even at high concentrations of GSSG in the absence of selenium. In contrast, the release of zinc from MT may occur very rapidly in presence of selenium compounds have the capacity to form selenol(ate)s (Maret 2003). The mechanism of the reaction was suggested to proceed through an activated selenenyl sulfide R-Se-S-G intermediate which, in turn, oxidizes the zinc-thiolate cluster of MT to form R-Se-S-MT with the concomitant release of zinc during the oxidation (Chen and Maret 2001). The selenol group is subsequently released by the attack of a nearby thiol group of MT that convert R-Se-S-MT into thionein generating a catalytic cycle of oxidative zinc release from MT. Other oxidized selenium compounds, such as selenoxide and selenic acid, may be directly reduced by MT through the formation of a R-Se-S-MT intermediate and the concomitant release of 
zinc, followed by the formation of an inter- or intramolecular disulfide bond (Jacob et al. 1999; Chen and Maret 2001; Klotz et al. 2003).

Selenium compounds also catalyze the release of zinc from MT in peroxidation and thiol/disulfide-interchange reactions. In presence of t-butylhydroperoxide, GPx catalyzes the oxidation of MT with subsequent zinc release, suggesting that MT may serve as reducing agents for GPx (or at least some GPx isoforms) in alternative to GSH (Jacob et al. 1999). These results suggest that zinc release is a significant aspect of the therapeutic antioxidant actions of selenium compounds in anti-inflammatory and anticarcinogenic agents. Hence, the assessment of intracellular labile zinc and selenoproteome during a challenge with oxidative compounds might be useful to understand the physiology of successful aging.

While there are no studies specifically addressing these aspects in humans, it is of interest to consider the results of a recent study that examined 18 elements in the brain, heart, kidney, and liver of 26 mammalian species, and studied their correlation with body mass and longevity (Ma et al. 2015).

$\mathrm{Zn}$ levels in liver and kidney showed strong, positive correlations with species Maximum Lifespan and Maximum Lifespan Residual whereas liver Se was the only element correlating negatively with all measures of longevity, although the correlations were relatively weak. It is interesting to relate this study with the finding that the naked mole rat (a rodent model of delayed aging with a life span $>28$ years) is characterized by a reduced utilization of selenium due to a specific defect in GPx1 expression (Kasaikina et al. 2011). A possible interpretation of these results is that there is a delicate balance between the beneficial aspects of Se, its toxicity, and other systems that support maintenance functions.

Supplementation studies with zinc and selenium in humans are also poor, especially with a focus on immunosenescence. Girodon et al. (1999) determined the effects of a long-term (for 2 years) daily supplementation with zinc $(20 \mathrm{mg})$ plus selenium $(100 \mu \mathrm{g})$ on immunity and the incidence of infections in a large number (n.725) of institutionalized elderly people ( $>65$ years). The main results of the study were: (1) selenium-deficient patients decreased from about $80 \%$ to $5-10 \%$ in the selenium supplemented group after 6 months of supplementation with respect to placebo group; (2) antibody titres after influenza vaccine were higher in groups that receive trace elements; and (3) trace element-supplemented patients were those who remained most free of respiratory tract infections than placebo group. These findings suggest that low dose supplementation of zinc and selenium provides significant improvement in elderly patients by increasing the humoral response after vaccination and decreased influenza compliances (respiratory tract infections) with thus a possible impact on the maintenance of health conditions during aging. However, conversely to the conventional belief and claims that supplementation with $\mathrm{Zn}$ and Se may improve health conditions there are important studies that observed lack of clear effects. The large SU.VI.MAX trial conducted with a supplement of antioxidant including zinc and selenium reported no effects on health-related quality of life after 76 months of supplementation in 8112 French adults (Briançon et al. 2011). In addition, supplementation with low or medium doses of zinc and selenium provided no benefits, neither were able to correct low zinc or selenium status in hemodialysis patients (Tonelli et al. 2015). In conclusion, conversely to the past belief that zinc 
and selenium supplements could be used as elixir of long life, recent epidemiologic and laboratory studies are changing our perception of the biological effects of these essential trace elements.

\section{Conclusions and Future Remarks}

While several studies suggest that correcting zinc and selenium deficiency in aging provide a beneficial impact on immunosenescence, it is evident that controversial finding exists on the "real" necessity of micronutrient supplementation (Dangour et al. 2004). The critical step of supplementation strategies with zinc and selenium still remains the diagnosis of zinc and selenium deficiency, as there are no validated methods to assess their status in aging. However, in the case of documented deficiency, it seems to make sense to provide selenium supplements associated with zinc and even with additional supplements. Indeed, micronutrient deficiencies are usually not isolated and some biochemical mechanisms involved in the action of selenium are under the control of zinc ion bioavailability. In other words, the attempt to correct selenium deficiency alone may result in lack of beneficial effects due to the presence of zinc or other micro- and macronutrient deficiency. Many points still require further investigations, first of all, the possible involvement of MT, zinc, and selenium in antagonistic pleiotropic mechanisms that regulate mammalian life span. One of these mechanisms is cellular senescence, which has gained considerable attention in these last years as a useful anti-aging target. Useful tools are available, such as NO donors and zinc fluorescent probes (zinpyr-1 and fluozin-3) to help researcher in the quantitative assessment of labile zinc and on the functional role of MT (Malavolta et al. 2006; Haase et al. 2006) in senescent cells. These tools applied in supplementation trials performed in animal models that allow to visualize, sort, and selectively eliminate senescent cells (Demaria et al. 2014) could help to clarify these mechanisms. Additional insight could be provided by the investigation of serum trace elements associated with MT induction in PBMC obtained from centenarian's offspring in the framework of Markage project (Bürkle et al. 2015). The results may help to understand the physiological mechanisms involved in healthy aging and may help to understand new strategies for nutritional or pharmacological intervention aimed at increased longevity in healthy conditions.

Acknowledgments The study has been partially funded through the revenues of the " 5 per Mille" donations received by INRCA through the Italian Ministry of Health. The authors declare that there are no conflicts of interest.

\section{References}

Abo T, Kawamura T, Watanabe H (2000) Physiological responses of extrathymic T cells in the liver. Immunol Rev 174:135-149

Akbaraly NT, Arnaud J, Hininger-Favier I et al (2005) Selenium and mortality in the elderly: results from the EVA study. Clin Chem 51:2117-2123. https://doi.org/10.1373/clinchem.2005.055301 
Alehagen U, Aaseth J, Johansson P (2015) Reduced cardiovascular mortality 10 years after supplementation with selenium and coenzyme Q10 for four years: follow-up results of a prospective randomized double-blind placebo-controlled trial in elderly citizens. PLoS One 10:e0141641. https://doi.org/10.1371/journal.pone.0141641

Alehagen U, Johansson P, Björnstedt M et al (2016) Relatively high mortality risk in elderly Swedish subjects with low selenium status. Eur J Clin Nutr 70:91-96. https://doi.org/10.1038/ ejen.2015.92

Alissa EM, Bahijri SM, Ferns GA (2003) The controversy surrounding selenium and cardiovascular disease: a review of the evidence. Med Sci Monit 9:RA9-R18

Ames BN (2006) Low micronutrient intake may accelerate the degenerative diseases of aging through allocation of scarce micronutrients by triage. Proc Natl Acad Sci USA 103: 17589-17594. https://doi.org/10.1073/pnas.0608757103

Andree KB, Kim J, Kirschke CP et al (2004) Investigation of lymphocyte gene expression for use as biomarkers for zinc status in humans. J Nutr 134:1716-1723

Arakawa T, Deguchi T, Sakazaki F et al (2013) Supplementary seleno-L-methionine suppresses active cutaneous anaphylaxis reaction. Biol Pharm Bull 36:1969-1974

Arnaud J, Bertrais S, Roussel AM et al (2006) Serum selenium determinants in French adults: the SU.VI.M.AX study. Br J Nutr 95:313-320

Arner ES, Holmgren A (2000) Physiological functions of thioredoxin and thioredoxin reductase. Eur J Biochem 267:6102-6109

Aro A, Alfthan G, Varo P (1995) Effect of supplementation of fertilizers on human selenium status in Finland. Analyst 120:841-843

Arriaga JM, Greco A, Mordoh J, Bianchini M (2014) Metallothionein $1 \mathrm{G}$ and zinc sensitize human colorectal cancer cells to chemotherapy. Mol Cancer Ther 13:1369-1381. https://doi.org/10.11 58/1535-7163.MCT-13-0944

Arthur JR (2003) Selenium supplementation: does soil supplementation help and why? Proc Nutr Soc 62:393-397

Arthur JR, McKenzie RC, Beckett GJ (2003) Selenium in the immune system. J Nutr 133: $1457 \mathrm{~S}-1459 \mathrm{~S}$

Arvin AM (1996) Varicella-zoster virus. Clin Microbiol Rev 9:361-381

Assmann A, Briviba K, Sies H (1998) Reduction of methionine selenoxide to selenomethionine by glutathione. Arch Biochem Biophys 349:201-203

Assmann KE, Andreeva VA, Jeandel C et al (2015) Healthy aging 5 years after a period of daily supplementation with antioxidant nutrients: a post hoc analysis of the French randomized trial SU.VI.MAX. Am J Epidemiol 182:694-704. https://doi.org/10.1093/aje/kwv105

Bailey RL, West KP Jr, Black RE (2015) The epidemiology of global micronutrient deficiencies. Ann Nutr Metab 66:22-33

Baker DJ, Wijshake T, Tchkonia T et al (2011) Clearance of p16Ink4a-positive senescent cells delays ageing-associated disorders. Nature 479:232-236. https://doi.org/10.1038/nature10600

Baker DJ, Childs BG, Durik M et al (2016) Naturally occurring p16(Ink4a)-positive cells shorten healthy lifespan. Nature 530:184-189. https://doi.org/10.1038/nature16932

Barnett JB, Dao MC, Hamer DH et al (2016) Effect of zinc supplementation on serum zinc concentration and $\mathrm{T}$ cell proliferation in nursing home elderly: a randomized, double-blind, placebo-controlled trial. Am J Clin Nutr 103:942-951. https://doi.org/10.3945/ajcn.115.115188

Beck MA (1999) Selenium and host defence towards viruses. Proc Nutr Soc 58:707-711

Beck MA, Levander OA (2000) Host nutritional status and its effect on a viral pathogen. J Infect Dis 182:S93-S96

Beck MA, Levander OA, Handy J (2003) Selenium deficiency and viral infection. J Nutr 133:1463

Beckett GJ, Arthur JR (2005) Selenium and endocrine systems. J Endocrinol 184:455-465. https:// doi.org/10.1677/joe.1.05971

Beckett GJ, Arthur JR, Miller SM, McKenzie RC (2004) Selenium. In: Bendick A, Darlington G (eds) Diet and human immune function. Humana Press, Totowa, pp 217-240

Beilstein MA, Whanger PD (1986) Deposition of dietary organic and inorganic selenium in rat erythrocyte proteins. J Nutr 116:1701-1710 
Berg JM, Shi Y (1996) The galvanization of biology: a growing appreciation for the roles of zinc. Science 271:1081-1085

Bhaskaram P (2002) Micronutrient malnutrition, infection, and immunity: an overview. Nutr Rev 60:S40-S45. https://doi.org/10.1301/00296640260130722

Biswas S, Talukder G, Sharma A (2000) Chromosome damage induced by selenium salts in human peripheral lymphocytes. Toxicol In Vitro 14:405-408

Bjelakovic G, Gluud C (2011) Vitamin and mineral supplement use in relation to all-cause mortality in the Iowa Women's Health Study. Arch Intern Med 171:1633-1634. https://doi.org/10.1001/ archinternmed.2011.459

Björnstedt M, Hamberg M, Kumar S et al (1995) Human thioredoxin reductase directly reduces lipid hydroperoxides by NADPH and selenocystine strongly stimulates the reaction via catalytically generated selenols. J Biol Chem 270:11761-11764

Blot WJ, Li JY, Taylor PR et al (1995) The Linxian trials: mortality rates by vitamin-mineral intervention group. Am J Clin Nutr 62:1424S-1426S

Bogdan C, Rollinghoff M, Diefenbach A (2000) The role of nitric oxide in innate immunity. Immunol Rev 173:17-26

Bogden JD, Oleske JM, Lavenhar MA et al (1990) Effects of one year of supplementation with zinc and other micronutrients on cellular immunity in the elderly. J Am Coll Nutr 9:214-225

Boukaïba N, Flament C, Acher S et al (1993) A physiological amount of zinc supplementation: effects on nutritional, lipid, and thymic status in an elderly population. Am J Clin Nutr 57:566-572

Briançon S, Boini S, Bertrais S et al (2011) Long-term antioxidant supplementation has no effect on health-related quality of life: the randomized, double-blind, placebo-controlled, primary prevention SU.VI.MAX trial. Int J Epidemiol 40:1605-1616. https://doi.org/10.1093/ije/dyr161

Brigelius-Flohé R (1999) Tissue-specific functions of individual glutathione peroxidases. Free Radic Biol Med 27:951-965

Burk RF, Hill KE, Motley AK (2003) Selenoprotein metabolism and function: evidence for more than one function for selenoprotein P. J Nutr 133:1517S-1520S

Bürkle A, Caselli G, Franceschi C et al (2007) Pathophysiology of ageing, longevity and age related diseases. Immun Ageing 4:4. https://doi.org/10.1186/1742-4933-4-4

Bürkle A, Moreno-Villanueva M, Bernhard J et al (2015) MARK-AGE biomarkers of ageing. Mech Ageing Dev 151:2-12. https://doi.org/10.1016/j.mad.2015.03.006

Buttriss J (2000) Nutrient requirements and optimisation of intakes. Br Med Bull 56:18-33. https:// doi.org/10.1258/0007142001902941

Cai L, Satoh M, Tohyama C, Cherian MG (1999) Metallothionein in radiation exposure: its induction and protective role. Toxicology 132:85-98

Cakman I, Kirchner H, Rink L (1997) Zinc supplementation reconstitutes the production of interferon-alpha by leukocytes from elderly persons. J Interf Cytokine Res 17:469-472

Campisi J (2014) Cell biology: the beginning of the end. Nature 505:35-36. https://doi.org/10.10 38/nature12844

Cemeli E, Marcos R, Anderson D (2006) Genotoxic and antigenotoxic properties of selenium compounds in the in vitro micronucleus assay with human whole blood lymphocytes and TK6 lymphoblastoid cells. ScientificWorldJournal 6:1202-1210. https://doi.org/10.1100/tsw.2006. 204

Chang J, Wang Y, Shao L et al (2016) Clearance of senescent cells by ABT263 rejuvenates aged hematopoietic stem cells in mice. Nat Med 22:78-83

Chen Y, Maret W (2001) Catalytic oxidation of zinc/sulfur coordination sites in proteins by selenium compounds. Antioxid Redox Signal 3:651-656

Chen Y-C, Prabhu KS, Das A, Mastro AM (2013) Dietary selenium supplementation modifies breast tumor growth and metastasis. Int J Cancer 133:2054-2064. https://doi.org/10.1002/ijc. 28224

Chernoff R (2001) Nutrition and health promotion in older adults. J Gerontol A Biol Sci Med Sci 56 Spec No 2:47-53. https://doi.org/10.1093/gerona/56.suppl_2.47

Cipriano C, Malavolta M, Costarelli L et al (2006) Polymorphisms in MT1a gene coding region are associated with longevity in Italian Central female population. Biogerontology 7:357-365. https://doi.org/10.1007/s10522-006-9050-x 
Clark LC, Dalkin B, Krongrad A et al (1998) Decreased incidence of prostate cancer with selenium supplementation: results of a double-blind cancer prevention trial. Br J Urol 81:730-734

Clegg MS, Hanna LA, Niles BJ et al (2005) Zinc deficiency-induced cell death. IUBMB Life 57:661-669. https://doi.org/10.1080/15216540500264554

Coleman JE (1992) Zinc proteins: enzymes, storage proteins, transcription factors, and replication proteins. Annu Rev Biochem 61:897-946

Collado M, Gil J, Efeyan A et al (2005) Tumour biology: senescence in premalignant tumours. Nature 436:642. https://doi.org/10.1038/436642a

Combs GF (2001) Selenium in global food systems. Br J Nutr 85:517-547

Coneyworth LJ, Mathers JC, Ford D (2009) Does promoter methylation of the SLC30A5 (ZnT5) zinc transporter gene contribute to the ageing-related decline in zinc status? Proc Nutr Soc 68:142-147. https://doi.org/10.1017/S0029665109001104

Coodley G (1995) Update on vitamins, minerals, and the carotenoids. J Physicians Assoc AIDS Care 2:24-29

Costarelli L, Giacconi R, Malavolta M et al (2014) Effects of zinc-fortified drinking skim milk (as functional food) on cytokine release and thymic hormone activity in very old persons: a pilot study. Age (Dordr) 36:9656. https://doi.org/10.1007/s11357-014-9656-x

Coto JA, Hadden EM, Sauro M et al (1992) Interleukin 1 regulates secretion of zinc-thymulin by human thymic epithelial cells and its action on T-lymphocyte proliferation and nuclear protein kinase C. Proc Natl Acad Sci USA 89:7752-7756

Cousins RJ, McMahon RJ (2000) Integrative aspects of zinc transporters. J Nutr 130:1384S-1387S

Czernichow S, Bertrais S, Blacher J et al (2005) Effect of supplementation with antioxidants upon long-term risk of hypertension in the SU.VI.MAX study: association with plasma antioxidant levels. J Hypertens 23:2013-2018

Dangour AD, Sibson VL, Ae F (2004) Micronutrient supplementation in later life: limited evidence for benefit. J Gerontol A Biol Sci Med Sci 59:659-673

Daniels LA (2004) Selenium: does selenium status have health outcomes beyond overt deficiency? Med J Aust 180:373-374

Dardenne M, Boukaiba N, Gagnerault MC et al (1993) Restoration of the thymus in aging mice by in vivo zinc supplementation. Clin Immunol Immunopathol 66:127-135

Das KC, Das CK (2000) Thioredoxin, a singlet oxygen quencher and hydroxyl radical scavenger: redox independent functions. Biochem Biophys Res Commun 277:443-447

Davis SR, Cousins RJ (2000) Metallothionein expression in animals: a physiological perspective on function. J Nutr 130:1085-1088

Delmas-Beauvieux MC, Peuchant E, Couchouron A et al (1996) The enzymatic antioxidant system in blood and glutathione status in human immunodeficiency virus (HIV)-infected patients: effects of supplementation with selenium or beta-carotene. Am J Clin Nutr 64:101-107

Demaria M, Ohtani N, Youssef SA et al (2014) An essential role for senescent cells in optimal wound healing through secretion of PDGF-AA. Dev Cell 31:722-733. https://doi.org/10.1016/j. devcel.2014.11.012

Dharmarajan TS (2015) Is vitamin supplementation appropriate in the healthy old? Curr Opin Gastroenterol 31:143-152. https://doi.org/10.1097/MOG.0000000000000150

Driessen C, Hirv K, Rink L, Kirchner H (1994) Induction of cytokines by zinc ions in human peripheral blood mononuclear cells and separated monocytes. Lymphokine Cytokine Res 13:15-20

Duarte EA, Novella IS, Weaver SC et al (1994) RNA virus quasispecies: significance for viral disease and epidemiology. Infect Agents Dis 3:201-214

Duchateau J, Delepesse G, Vrijens R, Collet H (1981) Beneficial effects of oral zinc supplementation on the immune response of old people. Am J Med 70:1001-1004

Dziegiel P, Pula B, Kobierzycki C et al (2016) The role of metallothioneins in carcinogenesis. Adv Anat Embryol Cell Biol 218:29-63. https://doi.org/10.1007/978-3-319-27472-0_4

Eckschlager T, Adam V, Hrabeta J et al (2009) Metallothioneins and cancer. Curr Protein Pept Sci 10:360-375

Eide DJ (2006) Zinc transporters and the cellular trafficking of zinc. Biochem Biophys Acta 1763:711-722 
Ellis SE, Coffey CS, Mitchel EF et al (2003) Influenza- and respiratory syncytial virus-associated morbidity and mortality in the nursing home population. J Am Geriatr Soc 51:761-767

Fabris N, Mocchegiani E, Amadio L et al (1984) Thymic hormone deficiency in normal ageing and Down's syndrome: is there a primary failure of the thymus? Lancet (London, England) 1:983-986

Farrokhian A, Bahmani F, Taghizadeh M et al (2016) Selenium supplementation affects insulin resistance and serum hs-CRP in patients with type 2 diabetes and coronary heart disease. Horm Metab Res $=$ Horm und Stoffwechselforsch $=$ Horm métabolisme 48:263-268. https://doi.org/ $10.1055 / \mathrm{s}-0035-1569276$

Feillet-Coudray C, Meunier N, Bayle D et al (2006) Effect of zinc supplementation on in vitro copper-induced oxidation of low-density lipoproteins in healthy French subjects aged 55-70 years: the Zenith Study. Br J Nutr 95:1134-1142

Forceville X, Vitoux D, Gauzit R et al (1998) Selenium, systemic immune response syndrome, sepsis, and outcome in critically ill patients. Crit Care Med 26:1536-1544

Fortes C, Agabiti N, Fano V et al (1997) Zinc supplementation and plasma lipid peroxides in an elderly population. Eur J Clin Nutr 51:97-101

Fortes C, Forastiere F, Agabiti N et al (1998) The effect of zinc and vitamin A supplementation on immune response in an older population. J Am Geriatr Soc 46:19-26

Fraker PJ (2005) Roles for cell death in zinc deficiency. J Nutr 135:359-362

Fraker PJ, Lill-Elghanian DA (2004) The many roles of apoptosis in immunity as modified by aging and nutritional status. J Nutr Health Aging 8:56-63

Franceschi C, Bonafè M, Valensin S et al (2000) Inflamm-aging. An evolutionary perspective on immunosenescence. Ann N Y Acad Sci 908:244-254. https://doi.org/10.1111/j.1749-6632.20 00.tb06651.x

Fulop T, Larbi A, Witkowski JM et al (2010) Aging, frailty and age-related diseases. Biogerontology 11:547-563

Ghyselinck NB, Dufaure I, Lareyre JJ et al (1993) Structural organization and regulation of the gene for the androgen-dependent glutathione peroxidase-like protein specific to the mouse epididymis. Mol Endocrinol 7:258-272. https://doi.org/10.1210/mend.7.2.8469239

Giacconi R, Cipriano C, Muti E et al (2005) Novel-209A/G MT2A polymorphism in old patients with type 2 diabetes and atherosclerosis: relationship with inflammation (IL-6) and zinc. Biogerontology 6:407-413. https://doi.org/10.1007/s10522-005-4907-y

Giacconi R, Malavolta M, Costarelli L et al (2012) Comparison of intracellular zinc signals in nonadherent lymphocytes from young-adult and elderly donors: role of zinc transporters (Zip family) and proinflammatory cytokines. J Nutr Biochem 23:1256-1263. https://doi.org/10.10 16/j.jnutbio.2011.07.005

Giacconi R, Simm A, Santos AN et al (2014) Influence of +1245 A/G MT1A polymorphism on advanced glycation end-products (AGEs) in elderly: effect of zinc supplementation. Genes Nutr 9:426. https://doi.org/10.1007/s12263-014-0426-2

Giacconi R, Costarelli L, Malavolta M et al (2015) Effect of ZIP2 Gln/Arg/Leu (rs2234632) polymorphism on zinc homeostasis and inflammatory response following zinc supplementation. Biofactors 41:414-423. https://doi.org/10.1002/biof.1247

Girodon F, Galan P, Monget AL et al. (1999) Impact of trace elements and vitamin supplementation on immunity and infections in institutionalized elderly patients: a randomized controlled trial. MIN. VIT. AOX. geriatric network. Arch Intern Med 59:748-54

Haase H, Rink L (2009) The immune system and the impact of zinc during aging. Immun Ageing 6:9. https://doi.org/10.1186/1742-4933-6-9

Haase H, Rink L (2014) Zinc signals and immune function. Biofactors 40:27-40

Haase H, Hebel S, Engelhardt G, Rink L (2006) Flow cytometric measurement of labile zinc in peripheral blood mononuclear cells. Anal Biochem 352:222-230. https://doi.org/10.1016/j.ab. 2006.02.009

Habeebu SS, Liu J, Liu Y, Klaassen CD (2000) Metallothionein-null mice are more susceptible than wild-type mice to chronic $\mathrm{CdCl}(2)$-induced bone injury. Toxicol Sci 56:211-219

Hainaut P, Mann K (2001) Zinc binding and redox control of p53 structure and function. Antioxid Redox Signal 3:611-623 
Hall L, Williams K, Perry AC et al (1998) The majority of human glutathione peroxidase type 5 (GPX5) transcripts are incorrectly spliced: implications for the role of GPX5 in the male reproductive tract. Biochem J 333(Pt 1):5-9

Hill CH (1976) Mineral interrelationships. In: Prasad AS (ed) Trace elements, human health and disease. Academic, New York, pp 281-300

Ho E, Ames BN (2002) Low intracellular zinc induces oxidative DNA damage, disrupts p53 NFkappa B, and AP1 DNA binding, and affects DNA repair in a rat glioma cell line. Proc Natl Acad Sci USA 99:16770-16775

Ho E, Courtemanche C, Ames BN (2003) Zinc deficiency induces oxidative DNA damage and increases p53 expression in human lung fibroblasts. J Nutr 133:2543-2548

Hodkinson CF, Kelly M, Alexander HD et al (2007) Effect of zinc supplementation on the immune status of healthy older individuals aged 55-70 years: the ZENITH Study. J Gerontol A Biol Sci Med Sci 62:598-608

Hoffmann FW, Hashimoto AC, Shafer LA et al (2010) Dietary selenium modulates activation and differentiation of CD4+ T cells in mice through a mechanism involving cellular free thiols. J Nutr 140:1155-1161. https://doi.org/10.3945/jn.109.120725

Holmgren A (1985) Thioredoxin. Annu Rev Biochem 54:237-271

Huang Z, Rose AH, Hoffmann PR (2012) The role of selenium in inflammation and immunity: from molecular mechanisms to therapeutic opportunities. Antioxid Redox Signal 16:705-743. https:// doi.org/10.1089/ars.2011.4145

Ibs KH, Rink L (2003) Zinc-altered immune function. J Nutr 133:5

Ivory K, Prieto E, Spinks C et al (2015) Selenium supplementation has beneficial and detrimental effects on immunity to influenza vaccine in older adults. Clin Nutr. https://doi.org/10.1016/j. clnu.2015.12.003

Iwata T, Incefy GS, Tanaka T et al (1979) Circulating thymic hormone levels in zinc deficiency. Cell Immunol 47:100-105

Jacob C, Maret W, Vallee BL (1999) Selenium redox biochemistry of zinc-sulfur coordination sites in proteins and enzymes. Proc Natl Acad Sci USA 96:1910-1914

Jacobs MM (1983) Selenium inhibition of 1,2-dimethylhydrazine-induced colon carcinogenesis. Cancer Res 43:1646-1649

Jariwalla RJ, Gangapurkar B, Nakamura D (2009) Differential sensitivity of various human tumourderived cell types to apoptosis by organic derivatives of selenium. Br J Nutr 101:182-189. https://doi.org/10.1017/S0007114508998305

Jun EJ, Ye JS, Hwang IS et al (2011) Selenium deficiency contributes to the chronic myocarditis in coxsackievirus-infected mice. Acta Virol 55:23-29

Kadota Y, Aki Y, Toriuchi Y et al (2015) Deficiency of metallothionein-1 and -2 genes shortens the lifespan of the 129/Sv mouse strain. Exp Gerontol 66:21-24. https://doi.org/10.1016/j.exger. 2015.04.007

Kagi JH, Schaffer A (1998) Biochemistry of metallothionein. Biochemistry 127:8509-8515

Kahmann L, Uciechowski P, Warmuth S et al (2008) Zinc supplementation in the elderly reduces spontaneous inflammatory cytokine release and restores $\mathrm{T}$ cell functions. Rejuvenation Res 11:227-237. https://doi.org/10.1089/rej.2007.0613

Kant AK (2000) Consumption of energy-dense, nutrient-poor foods by adult Americans: nutritional and health implications. The third National Health and Nutrition Examination Survey, 1988-1994. Am J Clin Nutr 72:929-936

Kasaikina MV, Lobanov AV, Malinouski MY et al (2011) Reduced utilization of selenium by naked mole rats due to a specific defect in GPx1 expression. J Biol Chem 286:17005-17014. https:// doi.org/10.1074/jbc.M110.216267

Kelly EJ, Quaife CJ, Froelick GJ, Palmiter RD (1996) Metallothionein I and II protect against zinc deficiency and zinc toxicity in mice. J Nutr 126:1782-1790

Kiremidjian-Schumacher L, Roy M, Glickman R et al (2000) Selenium and immunocompetence in patients with head and neck cancer. Biol Trace Elem Res 73:97-111. https://doi.org/10.1385/ BTER:73:2:97

Klotz L-O, Kröncke K-D, Buchczyk DP, Sies H (2003) Role of copper, zinc, selenium and tellurium in the cellular defense against oxidative and nitrosative stress. J Nutr 133:1448S-1451S 
Kohrle J (2000) The deiodinase family: selenoenzymes regulating thyroid hormone availability and action. Cell Mol Life Sci 57:1853-1863

Kondo Y, Rusnak JM, Hoyt DG et al (1997) Enhanced apoptosis in metallothionein null cells. Mol Pharmacol 52:195-201

Kristal AR, Darke AK, Morris JS et al (2014) Baseline selenium status and effects of selenium and vitamin e supplementation on prostate cancer risk. J Natl Cancer Inst 106:djt456. https://doi.org/ 10.1093/jnci/djt456

Kryukov GV, Castellano S, Novoselov SV et al (2003) Characterization of mammalian selenoproteomes. Science 300:1439-1443. https://doi.org/10.1126/science.1083516

Kumar J, Barhydt T, Awasthi A et al (2016) Zinc levels modulate lifespan through multiple longevity pathways in Caenorhabditis elegans. PLoS One 11:e0153513. https://doi.org/10.13 71/journal.pone. 0153513

Lashley FR (2006) Emerging infectious diseases at the beginning of the 21st century. Online J Issues Nurs 11:2-6

Leighton D, Goua M, Dolan E et al (2015) Can selenium supplementation modify oxidative stress in-vitro? A role for selenium supplementation in the prevention of cardiovascular disease. J Inflamm 12:P7. https://doi.org/10.1186/1476-9255-12-S1-P7

Lesourd B (2006) Nutritional factors and immunological ageing. Proc Nutr Soc 65:319-325. https://doi.org/10.1079/PNS2006507

Levine RL, Mosoni L, Berlett BS, Stadtman ER (1996) Methionine residues as endogenous antioxidants in proteins. Proc Natl Acad Sci USA 93:15036-15040

Li W, Beck MA (2007) Selenium deficiency induced an altered immune response and increased survival following influenza A/Puerto Rico/8/34 infection. Exp Biol Med (Maywood) 232:412-419

Li GS, Wang F, Kang D, Li C (1985) Keshan disease: an endemic cardiomyopathy in China. Hum Pathol 16:602-609

Li Y, Yang Y, Chen H (1995) Detection of enteroviral RNA in paraffin-embedded myocardial tissue from patients with Keshan by nested PCR. Zhonghua Yi Xue Za Zhi 75:344-345

Licastro F, Chiricolo M, Mocchegiani E et al (1994) Oral zinc supplementation in Down's syndrome subjects decreased infections and normalized some humoral and cellular immune parameters. J Intellect Disabil Res 38(Pt 2):149-162

Liu JZ, Milner JA (1992) Age, dietary selenium and quantity of 7,12-dimethylbenz(a)anthracene influence the in vivo occurrence of rat mammary DNA adducts. J Nutr 122:1361-1368

Liuzzi JP, Lichten LA, Rivera S et al (2005) Interleukin-6 regulates the zinc transporter Zip14 in liver and contributes to the hypozincemia of the acute-phase response. Proc Natl Acad Sci USA 102:6843-6848. https://doi.org/10.1073/pnas.0502257102

Loh SN (2010) The missing zinc: p53 misfolding and cancer. Metallomics 2:442-449. https://doi. org/10.1039/c003915b

Ma S, Lee S-G, Kim EB et al (2015) Organization of the mammalian ionome according to organ origin, lineage specialization, and longevity. Cell Rep 13:1319-1326. https://doi.org/10.1016/j. celrep.2015.10.014

Machado M da S, Villela IV, Moura DJ et al (2009) 3'3-ditrifluoromethyldiphenyl diselenide: a new organoselenium compound with interesting antigenotoxic and antimutagenic activities. Mutat Res 673:133-140. https://doi.org/10.1016/j.mrgentox.2009.01.003

Maggini S, Wintergerst ES, Beveridge S, Hornig DH (2007) Selected vitamins and trace elements support immune function by strengthening epithelial barriers and cellular and humoral immune responses. Br J Nutr 98(Suppl 1):S29-S35. https://doi.org/10.1017/S0007114507832971

Malavolta M, Costarelli L, Giacconi R et al (2006) Single and three-color flow cytometry assay for intracellular zinc ion availability in human lymphocytes with Zinpyr-1 and double immunofluorescence: relationship with metallothioneins. Cytometry A 69:1043-1053. https://doi.org/10. 1002/cyto.a.20335

Malavolta M, Cipriano C, Costarelli L et al (2008) Metallothionein downregulation in very old age: a phenomenon associated with cellular senescence? Rejuvenation Res 11:455-459. https://doi. org/10.1089/rej.2008.0679 
Malavolta M, Basso A, Piacenza F et al (2012) Survival study of metallothionein-1 transgenic mice and respective controls (C57BL/6J): influence of a zinc-enriched environment. Rejuvenation Res 15:140-143. https://doi.org/10.1089/rej.2011.1261

Malavolta M, Costarelli L, Giacconi R et al (2014) Modulators of cellular senescence: mechanisms, promises, and challenges from in vitro studies with dietary bioactive compounds. Nutr Res 34:1017-1035. https://doi.org/10.1016/j.nutres.2014.02.006

Malavolta M, Piacenza F, Basso A et al (2015) Serum copper to zinc ratio: relationship with aging and health status. Mech Ageing Dev 151:93-100. https://doi.org/10.1016/j.mad.2015.01.004

Malavolta M, Orlando F, Piacenza F et al (2016) Metallothioneins, longevity and cancer: comment on "Deficiency of metallothionein-1 and -2 genes shortens the lifespan of the 129/Sv mouse strain". Exp Gerontol 73:28-30. https://doi.org/10.1016/j.exger.2015.11.014

Mann JJ, Fraker PJ (2005) Zinc pyrithione induces apoptosis and increases expression of Bim. Apoptosis 10:369-379

Maret W (2003) Cellular zinc and redox states converge in the metallothionein/thionein pair. J Nutr 133:1460S-1462S

Maret W, Vallee BL (1998) Thiolate ligands in metallothionein confer redox activity on zinc clusters. Proc Natl Acad Sci USA 95:3478-3482

Mariani E, Neri S, Cattini L et al (2008) Effect of zinc supplementation on plasma IL-6 and MCP-1 production and NK cell function in healthy elderly: interactive influence of +647 MT1a and -174 IL-6 polymorphic alleles. Exp Gerontol 43:462-471. https://doi.org/10.1016/j.exger. 2007.12.003

McGarrity TJ, Peiffer LP (1993) Selenium and difluoromethylornithine additively inhibit DMH-induced distal colon tumor formation in rats fed a fiber-free diet. Carcinogenesis $14: 2335-2340$

McKenzie RC, Rafferty TS, Beckett GJ (1998) Selenium: an essential element for immune function. Immunol Today 19:342-345

McVoy MA, Adler SP (1989) Immunologic evidence for frequent age-related cytomegalovirus reactivation in seropositive immunocompetent individuals. J Infect Dis 160:1-10

Mertens K, Lowes DA, Webster NR et al (2015) Low zinc and selenium concentrations in sepsis are associated with oxidative damage and inflammation. Br J Anaesth 114:990-999

Meydani M (2001) Nutrition interventions in aging and age-associated disease. Ann N Y Acad Sci 928:226-235

Mills CF (1989) Zinc in human biology. Springer, London

Mocchegiani E, Santarelli L, Muzzioli M, Fabris N (1995) Reversibility of the thymic involution and of age-related peripheral immune dysfunctions by zinc supplementation in old mice. Int J Immunopharmacol 17:703-718

Mocchegiani E, Muzzioli M, Cipriano C, Giacconi R (1998) Zinc, T-cell pathways, aging: role of metallothioneins. Mech Ageing Dev 106:183-204. https://doi.org/10.1016/S0047-6374(98)001 $15-8$

Mocchegiani E, Muzzioli M, Giacconi R (2000a) Zinc and immunoresistance to infection in aging: new biological tools. Trends Pharmacol Sci 21:205-208

Mocchegiani E, Muzzioli M, Giacconi R (2000b) Zinc, metallothioneins, immune responses, survival and ageing. Biogerontology 1:133-143

Mocchegiani E, Giacconi R, Cipriano C et al (2002a) MtmRNA gene expression, via IL-6 and glucocorticoids, as potential genetic marker of immunosenescence: lessons from very old mice and humans. Exp Gerontol 37:349-357

Mocchegiani E, Giacconi R, Cipriano C et al (2002b) Metallothioneins (I+II) and thyroid-thymus axis efficiency in old mice: role of corticosterone and zinc supply. Mech Ageing Dev 123:675-694

Mocchegiani E, Muzzioli M, Giacconi R et al (2003) Metallothioneins/PARP-1/IL-6 interplay on natural killer cell activity in elderly: parallelism with nonagenarians and old infected humans. Effect of zinc supply. Mech Ageing Dev 124:459-468

Mocchegiani E, Giacconi R, Cipriano C et al (2004) The variations during the circadian cycle of liver CD1d-unrestricted NK1.1+TCR gamma/delta+ cells lead to successful ageing. Role of 
metallothionein/IL-6/gp130/PARP-1 interplay in very old mice. Exp Gerontol 39:775-788. https://doi.org/10.1016/j.exger.2004.01.014

Mocchegiani E, Giacconi R, Cipriano C et al (2007) Zinc, metallothioneins, and longevity-effect of zinc supplementation: zincage study. Ann N Y Acad Sci 1119:129-146. https://doi.org/10.1196/ annals. 1404.030

Mocchegiani E, Giacconi R, Costarelli L et al (2008) Zinc deficiency and IL-6 -174G/C polymorphism in old people from different European countries: effect of zinc supplementation. ZINCAGE study. Exp Gerontol 43:433-444. https://doi.org/10.1016/j.exger.2008.01.001

Mocchegiani E, Costarelli L, Basso A et al (2013) Metallothioneins, ageing and cellular senescence: a future therapeutic target. Curr Pharm Des 19:1753-1764

Mursu J, Robien K, Harnack LJ et al (2011) Dietary supplements and mortality rate in older women: the Iowa Women's Health Study. Arch Intern Med 171:1625-1633. https://doi.org/10.1001/ archinternmed.2011.445

Nakamuro K, Yoshikawa K, Sayato Y et al (1976) Studies on selenium-related compounds. V. Cytogenetic effect and reactivity with DNA. Mutat Res 40:177-184

Nelson HK, Shi Q, Van Dael P et al (2001) Host nutritional selenium status as a driving force for influenza virus mutations. FASEB J 15:1846-1848

Nordberg J, Arner ES (2001) Reactive oxygen species, antioxidants, and the mammalian thioredoxin system. Free Radic Biol Med 31:1287-1312

Olivieri O, Girelli D, Stanzial AM et al (1996) Selenium, zinc, and thyroid hormones in healthy subjects: low T3/T4 ratio in the elderly is related to impaired selenium status. Biol Trace Elem Res 51:31-41. https://doi.org/10.1007/BF02790145

Ostan R, Alberti S, Bucci L et al (2006) Effect of zinc ions on apoptosis in PBMCs from healthy aged subjects. Biogerontology 7:437-447. https://doi.org/10.1007/s10522-006-9059-1

Padmaja S, Squadrito GL, Lemercier JN et al (1996) Rapid oxidation of DL-selenomethionine by peroxynitrite. Free Radic Biol Med 21:317-322

Pawelec G, Akbar A, Caruso C et al (2005) Human immunosenescence: is it infectious? Immunol Rev 205:257-268. https://doi.org/10.1111/j.0105-2896.2005.00271.x

Pawelec G, Goldeck D, Derhovanessian E (2014) Inflammation, ageing and chronic disease. Curr Opin Immunol 29:23-28

Pedersen MØ, Larsen A, Stoltenberg M, Penkowa M (2009) The role of metallothionein in oncogenesis and cancer prognosis. Prog Histochem Cytochem 44:29-64. https://doi.org/10.10 16/j.proghi.2008.10.001

Pence BC, Buddingh F (1985) Effect of dietary selenium deficiency on incidence and size of 1,2-dimethylhydrazine-induced colon tumours in rats. J Nutr 115:1196-1202

Peretz A, Nève J, Desmedt J et al (1991) Lymphocyte response is enhanced by supplementation of elderly subjects with selenium-enriched yeast. Am J Clin Nutr 53:1323-1328

Prasad AS (1993) Biochemistry of zinc. Plenum Press, New York

Prasad AS, Fitzgerald JT, Hess JW et al (1993) Zinc deficiency in elderly patients. Nutrition 9:218-224

Provinciali M, Di Stefano G, Stronati S (1998) Flow cytometric analysis of CD3/TCR complex, zinc, and glucocorticoid-mediated regulation of apoptosis and cell cycle distribution in thymocytes from old mice. Cytometry 32:1-8

Provinciali M, Pierpaoli E, Piacenza F et al (2016) Chapter 22 - Nutritional modulators of cellular senescence in vitro. In: Malavolta M, Mocchegiani E (eds) Molecular basis of nutrition and aging. Academic Press, London, pp 293-312. https://doi.org/10.1016/B978-0-12-801816-3.00022-4

Putics A, Vödrös D, Malavolta M et al (2008) Zinc supplementation boosts the stress response in the elderly: Hsp70 status is linked to zinc availability in peripheral lymphocytes. Exp Gerontol 43:452-461. https://doi.org/10.1016/j.exger.2008.01.002

Range N, Changalucha J, Krarup H et al (2006) The effect of multi-vitamin/mineral supplementation on mortality during treatment of pulmonary tuberculosis: a randomised two-by-two factorial trial in Mwanza, Tanzania. Br J Nutr 95:762-770

Rattan SIS (2016) Molecular and cellular basis of aging. In: Malavolta M, Mocchegiani E (eds) Molecular basis of nutrition and ageing, 1st edn. Academic, San Diego, pp 3-7

Rayman MP (2000) The importance of selenium to human health. Lancet 356:233-241 
Reid ME, Duffield-Lillico AJ, Garland L et al (2002) Selenium supplementation and lung cancer incidence: an update of the nutritional prevention of cancer trial. Cancer Epidemiol Biomark Prev 11:1285-1291

Reynolds MG, Anh BH, Thu VH et al (2006) Factors associated with nosocomial SARS-CoV transmission among healthcare workers in Hanoi, Vietnam, 2003. BMC Public Health 6:207. https://doi.org/10.1186/1471-2458-6-207

Rink L, Gabriel P (2000) Zinc and the immune system. Proc Nutr Soc 59:541-552

Rink L, Haase H (2007) Zinc homeostasis and immunity. Trends Immunol 28:1-4

Rodríguez-Sosa M, García-Montalvo EA, Del Razo LM, Vega L (2013) Effect of selenomethionine supplementation in food on the excretion and toxicity of arsenic exposure in female mice. Biol Trace Elem Res 156:279-287. https://doi.org/10.1007/s12011-013-9855-9

Roos CM, Zhang B, Palmer AK et al (2016) Chronic senolytic treatment alleviates established vasomotor dysfunction in aged or atherosclerotic mice. Aging Cell 15:973-977

Roveri A, Maiorino M, Nisii C, Ursini F (1994) Purification and characterization of phospholipid hydroperoxide glutathione peroxidase from rat testis mitochondrial membranes. Biochim Biophys Acta 1208:211-221

Roy M, Kiremidjian-Schumacher L, Wishe HI et al (1995) Supplementation with selenium restores age-related decline in immune cell function. Proc Soc Exp Biol Med 209:369-375

Rundlof AK, Arner ES (2004) Regulation of the mammalian selenoprotein thioredoxin reductase 1 in relation to cellular phenotype, growth, and signaling events. Antioxid Redox Signal $6: 41-52$

Safir N, Wendel A, Saile R, Chabraoui L (2003) The effect of selenium on immune functions of J774.1 cells. Clin Chem Lab Med 41:1005-1011. https://doi.org/10.1515/CCLM.2003.154

Sandstead HH (1995) Requirements and toxicity of essential trace elements, illustrated by zinc and copper. Am J Clin Nutr 61:621

Sandstead HH, Henriksen LK, Greger JL et al (1982) Zinc nutriture in the elderly in relation to taste acuity, immune response, and wound healing. Am J Clin Nutr 36:1046-1059

Sato M, Kondoh M (2002) Recent studies on metallothionein: protection against toxicity of heavy metals and oxygen free radicals. Tohoku J Exp Med 196:9-22

Satoh M, Nishimura N, Kanayama Y et al (1997) Enhanced renal toxicity by inorganic mercury in metallothionein-null mice. J Pharmacol Exp Ther 283:1529-1533

Savarino L, Granchi D, Ciapetti G et al (2001) Serum concentrations of zinc and selenium in elderly people: results in healthy nonagenarians/centenarians. Exp Gerontol 36:327-339

Savino W, Huang PC, Corrigan A et al (1984) Thymic hormone-containing cells. V. Immunohistological detection of metallothionein within the cells bearing thymulin (a zinc-containing hormone) in human and mouse thymuses. J Histochem Cytochem 32:942-946

Schwarz S (1976) Essentiality and metabolic functions of selenium. Med Clin North Am 60:745-758

Seiler WO (2001) Clinical pictures of malnutrition in ill elderly subjects. Nutrition 17:496-498

Semba RD, Bartali B, Zhou J et al (2006) Low serum micronutrient concentrations predict frailty among older women living in the community. J Gerontol A Biol Sci Med Sci 61:594-599. https://doi.org/10.1093/gerona/61.6.594

Sharif R, Thomas P, Zalewski P et al (2011) The effect of zinc sulphate and zinc carnosine on genome stability and cytotoxicity in the WIL2-NS human lymphoblastoid cell line. Mutat Res 720:22-33

Shenoy KT, Lena KB, Sali N et al (2006) Rationale and design for the CARDIOVIT Study (Cardiovit, Atherosclerotic vascular disease and hypeRhomocysteinemia: an epiDemiological study in Indians, additionally evaluating the effect of Oral VITamin supplementation). Curr Med Res Opin 22:641-648. https://doi.org/10.1185/030079906X96344

Stowe RP, Kozlova EV, Yetman DL et al (2007) Chronic herpesvirus reactivation occurs in aging. Exp Gerontol 42:563-570. https://doi.org/10.1016/j.exger.2007.01.005

Taylor GA, Blackshear PJ (1995) Zinc inhibits turnover of labile mRNAs in intact cells. J Cell Physiol 162:378-387

Thiesen HJ, Bach C (1991) Transition metals modulate DNA-protein interactions of SP1 zinc finger domains with its cognate target site. Biochem Biophys Res Commun 176:551-557 
Thomson CD (2004) Assessment of requirements for selenium and adequacy of selenium status: a review. Eur J Clin Nutr 58:391-402

Tian X, Zheng Y, Li Y et al (2014) Psychological stress induced zinc accumulation and up-regulation of ZIP14 and metallothionein in rat liver. BMC Gastroenterol 14:32. https://doi. org/10.1186/1471-230X-14-32

Tonelli M, Wiebe N, Thompson S et al (2015) Trace element supplementation in hemodialysis patients: a randomized controlled trial. BMC Nephrol 16:52. https://doi.org/10.1186/s12882015-0042-4

Tsuji PA, Carlson BA, Anderson CB et al (2015) Dietary selenium levels affect selenoprotein expression and support the interferon- $\gamma$ and IL-6 immune response pathways in mice. Forum Nutr 7:6529-6549. https://doi.org/10.3390/nu7085297

Turner RJ, Finch JM (1991) Selenium and the immune response. Proc Nutr Soc 50:275-285

Turnlund JR, Durkin N, Costa F, Margen S (1986) Stable isotope studies of zinc absorption and retention in young and elderly men. J Nutr 116:1239-1247

Uciechowski P, Kahmann L, Plümäkers B et al (2008) TH1 and TH2 cell polarization increases with aging and is modulated by zinc supplementation. Exp Gerontol 43:493-498. https://doi.org/ 10.1016/j.exger.2007.11.006

Valdiglesias V, Pásaro E, Méndez J, Laffon B (2010) In vitro evaluation of selenium genotoxic, cytotoxic, and protective effects: a review. Arch Toxicol 84:337-351. https://doi.org/10.1007/ s00204-009-0505-0

Vallee BL, Falchuk KH (1993) The biochemical basis of zinc physiology. Physiol Rev 73:79-118

Varin A, Larbi A, Dedoussis GV et al (2008) In vitro and in vivo effects of zinc on cytokine signalling in human T cells. Exp Gerontol 43:472-482. https://doi.org/10.1016/j.exger.2007. 12.008

Vinceti M, Dennert G, Crespi CM et al (2014) Selenium for preventing cancer. Cochrane Database Syst Rev 3:CD005195. https://doi.org/10.1002/14651858.CD005195.pub3

von Bulow V, Rink L, Haase H (2005) Zinc-mediated inhibition of cyclic nucleotide phosphodiesterase activity and expression suppresses TNF-alpha and IL-1 beta production in monocytes by elevation of guanosine 3',5'-cyclic monophosphate. J Immunol 175:4697-4705

Walter R, Roy J (1971) Selenomethionine, a potential catalytic antioxidant in biological systems. J Org Chem 36:2561-2563

Wasowicz W, Gromadzinska J, Rydzynski K, Tomczak J (2003) Selenium status of low-selenium area residents: polish experience. Toxicol Lett 137:95-101

Watson WH, Yang X, Choi YE et al (2004) Thioredoxin and its role in toxicology. Toxicol Sci 78:3-14. https://doi.org/10.1093/toxsci/kfh050

Wei W-Q, Abnet CC, Qiao Y-L et al (2004) Prospective study of serum selenium concentrations and esophageal and gastric cardia cancer, heart disease, stroke, and total death. Am J Clin Nutr 79:80-85

West AK, Stallings R, Hildebrand CE et al (1990) Human metallothionein genes: structure of the functional locus at $16 \mathrm{q} 13$. Genomics 8:513-518

Wiseman DA, Wells SM, Wilham J et al (2006) Endothelial response to stress from exogenous Zn2 + resembles that of NO-mediated nitrosative stress, and is protected by MT-1 overexpression. Am J Physiol Cell Physiol 291:C555-C568. https://doi.org/10.1152/ajpcell.00509.2005

Wolvers DAW, van Herpen-Broekmans WMR, Logman MHGM et al (2006) Effect of a mixture of micronutrients, but not of bovine colostrum concentrate, on immune function parameters in healthy volunteers: a randomized placebo-controlled study. Nutr J 5:28. https://doi.org/10.1186/ 1475-2891-5-28

Wong CP, Song Y, Elias VD et al (2009) Zinc supplementation increases zinc status and thymopoiesis in aged mice. J Nutr 139(7):1393. https://doi.org/10.3945/jn.109.106021

Wong CP, Magnusson KR, Ho E (2013) Increased inflammatory response in aged mice is associated with age-related zinc deficiency and zinc transporter dysregulation. J Nutr Biochem 24:353-359. https://doi.org/10.1016/j.jnutbio.2012.07.005

Wycherly BJ, Moak MA, Christensen MJ (2004) High dietary intake of sodium selenite induces oxidative DNA damage in rat liver. Nutr Cancer 48:78-83. https://doi.org/10.1207/s153279 14nc4801_11 
Xia Y, Hill KE, Byrne DW et al (2005) Effectiveness of selenium supplements in a low-selenium area of China. Am J Clin Nutr 81:829-834

Yang X, Doser TA, Fang CX et al (2006) Metallothionein prolongs survival and antagonizes senescence-associated cardiomyocyte diastolic dysfunction: role of oxidative stress. FASEB J 20:1024-1026. https://doi.org/10.1096/fj.05-5288fje

Yin X, Knecht DA, Lynes MA (2005) Metallothionein mediates leukocyte chemotaxis. BMC Immunol 6:21-31

Yona L, Zahia T-H, Laurent C (2014) Interplay between selenium levels, selenoprotein expression, and replicative senescence in WI-38 human fibroblasts. Free Radic Biol Med 75(Suppl 1):S25. https://doi.org/10.1016/j.freeradbiomed.2014.10.744

Youn J, Lynes MA (1999) Metallothionein-induced suppression of cytotoxic T lymphocyte function: an important immunoregulatory control. Toxicol Sci 52:199-208

Zangger K, Oz G, Haslinger E et al (2001) Nitric oxide selectively releases metals from the aminoterminal domain of metallothioneins: potential role at inflammatory sites. FASEB J 15:1303-1305

Zhang J, Peng D, Lu H, Liu Q (2008) Attenuating the toxicity of cisplatin by using selenosulfate with reduced risk of selenium toxicity as compared with selenite. Toxicol Appl Pharmacol 226:251-259. https://doi.org/10.1016/j.taap.2007.09.010

Zhang J, Wang X, Vikash V et al (2016) ROS and ROS-mediated cellular signaling. Oxidative Med Cell Longev 2016:4350965. https://doi.org/10.1155/2016/4350965 